\title{
Teaching New Markets Old Tricks: The Effects of Subsidized Investment on Low-Income Neighborhoods
}

\begin{abstract}
Matthew Freedman*
This paper examines the effects of investment subsidized by the federal government's New Markets Tax Credit (NMTC) program, which provides tax incentives to encourage private investment in low-income neighborhoods. I identify the impacts of the program by taking advantage of a discontinuity in the rule determining the eligibility of census tracts for NMTC-subsidized investment. Using this discontinuity as a source of quasi-experimental variation in commercial development across tracts, I find that subsidized investment has modest positive effects on neighborhood conditions in low-income communities. Though spillovers appear to be small and crowd out incomplete, the results suggest that some of the observed impacts on neighborhoods are attributable to changes in the composition of residents as opposed to improvements in the welfare of existing residents.
\end{abstract}

\section{Introduction}

Over the past several decades, the federal government in the U.S. has revisited its approach to tackling the problem of persistent poverty in low-income communities. Greater emphasis has been placed on market-based incentive schemes that rely on the private sector to provide resources perceived as necessary to alleviate poverty and blight in distressed cities and neighborhoods. As interest in business-oriented mechanisms to address stagnation in disadvantaged communities grew, a number of new programs emerged that attempt to encourage private investments in low-income areas, often using tax incentives.

This paper evaluates the effectiveness of the New Markets Tax Credit (NMTC) program in reducing poverty and improving other neighborhood conditions over the course of the 2000s. The NMTC, which was signed into law in 2000 as part of the Community Renewal Tax Relief

\footnotetext{
* Department of Economics, 262 Ives Faculty Building, Cornell University, Ithaca, NY 14853. Email: freedman@cornell.edu. Telephone: 607-254-8245.
} 
Act, arose out a desire to encourage private capital investment in neighborhoods thought to be overlooked during the economic boom of the 1990s. The program provides tax credits to investors who make equity investments in Community Development Entities. These entities are charged with investing the proceeds from the equity investments in businesses and real estate projects in certain designated low-income census tracts.

In order to identify the effects of NMTC-subsidized investment on neighborhood conditions, I take advantage of a discontinuity in the formula used to designate tracts as low-income. The discontinuity generates pseudo-random assignment of investment in tracts around a certain income threshold. Tracts below the threshold are eligible to receive NMTC-subsidized investment, whereas those above it are generally not eligible. However, on all other dimensions, the tracts on either side of the threshold are similar. Hence, comparing outcomes among tracts within a sufficiently narrow window around the cutoff permits one to draw causal inferences regarding the effects of investment subsidized by the NMTC on neighborhood conditions.

Using data from the 2000 Decennial Census and the 2005-2009 American Community Survey, I find modest benefits associated with subsidized investment targeted at low-income neighborhoods. Poverty and unemployment rates fall by statistically significant amounts in tracts that receive NMTC-subsidized investment relative to similar tracts that do not. While also positive, the estimated impacts on other neighborhood characteristics, including house values, are statistically indistinguishable from zero. Moreover, household turnover rates in affected communities are slightly higher, which suggests that the observed changes in neighborhood characteristics may not be entirely driven by improvements in the conditions of existing residents, but rather may at least in part be attributable to changes in neighborhood composition in the wake of new investment. Consistent with the modest positive impact of subsidized investment I find using survey data from residents, I also detect small but positive effects on total employment and the quality of jobs using administrative data derived from unemployment insurance tax records. Finally, the results suggest that while the NMTC program may redirect some investment dollars from higher to lower income areas and could crowd out some unsubsidized investment, spillovers are not large and crowd out is not complete.

This paper makes several important contributions. First, I shed new light on the effectiveness of tax incentives in encouraging local economic development. Much of what we know about the 
usefulness of tax incentives in revitalizing communities comes from work on state enterprise zones (EZs). State EZs provide tax incentives to new and expanding businesses in designated cities and neighborhoods. These incentives can take the form of employment credits or income, property, or sales tax breaks. Evaluating the effectiveness of EZs has proven challenging, in part because of the high degree of variation in program characteristics across states; not only do programs differ in the generosity and types of incentives offered to businesses, but they also vary in the criteria used to determine communities' eligibility for the program. As a result, the findings of existing studies on the effects of the EZs are mixed. Several papers, such as Papke (1994), Billings (2009), Ham et al. (2011) and Freedman (2012), find positive effects of EZs on local economic activity and neighborhood conditions. ${ }^{1}$ However, Boarnet and Bogart (1996), Elvery (2009), Neumark and Kolko (2010), and others find that EZs have little or no effect on local employment, casting doubt on the effectiveness of tax incentives in spurring growth in targeted areas. ${ }^{2}$

More broadly, this paper contributes to the growing literature on the impact of a new generation of place-based policies in the U.S. Much of this research has focused narrowly on housing policy (e.g., Baum-Snow and Marion 2009, Gabriel and Rosenthal 2009, Freedman and Owens 2011). The work that has been done outside housing has typically struggled with identification, often due to nonrandom selection of communities into programs. I exploit plausibly exogenous variation in subsidized investment across communities that results from federal rules determining the eligibility of census tracts for NMTC funds.

The paper is organized as follows. The next section provides background on the NMTC program. Section 3 details my econometric approach. After describing the data and providing descriptive statistics in Section 4, I present results on the spatial distribution of NMTCsubsidized investment in Section 5. Section 6 examines how this investment affects housing and resident characteristics in low-income communities. Section 7 takes up the issue of crowd out and the impact of subsidized investment on employment and the composition of jobs in lowincome communities. Section 8 concludes.

\footnotetext{
${ }^{1}$ Recent work on federal Empowerment Zones and Enterprise Communities, which were first established in 1994, suggests that they have increased economic activity in targeted areas (Busso et al. 2011, Ham et al. 2011).

${ }^{2}$ Notably, most EZ programs involve employment tax credits and target high poverty areas. In contrast, the NMTC program uses investment subsidies and targets only moderately low-income areas.
} 


\section{The New Markets Tax Credit Program}

\subsection{Program structure}

Introduced in the late $1990 \mathrm{~s}$ as a pro-business way to stimulate investment in the nation's distressed areas, the NMTC program was signed into law in December 2000 as part of the Community Renewal Tax Relief Act of $2000{ }^{3}$ Administered by the Community Development Financial Institutions (CDFI) Fund at the U.S. Department of the Treasury, the NMTC program, which allocated a total of \$26 billion in tax credits between fiscal years 2002 and 2009, encourages capital investment in businesses that are located in low-income neighborhoods by offering tax incentives to investors who make qualified equity investments (QEIs) in Community Development Entities (CDEs). ${ }^{4}$ The credit totals $39 \%$ of the cost of the investment and is claimed over a seven-year credit allowance period, with $5 \%$ being claimed over the first three years and $6 \%$ over the final four years.

CDEs are domestic corporations or partnerships that meet several criteria. First, their primary mission must be to serve or provide investment capital to low-income communities or persons. Second, CDEs must maintain accountability to the community by including resident representation on any governing or advisory board. Finally, CDEs must be certified by the CDFI Fund. A CDE remains certified for the life of the organization as long as it continues to meet the mission and accountability requirements. As of December 2011, there were 5,473 CDEs distributed across all 50 states and the District of Columbia. ${ }^{5}$ Among the currently certified CDEs are community development financial institutions, community development corporations, other non-profit financial intermediaries, government agencies, commercial and investment banks, and other for-profit financial institutions (Armistead 2005).

Each fiscal year between 2003 and 2009, between 40 and 100 CDEs received tax credit allocation rights totaling between $\$ 2$ billion and $\$ 5$ billion. ${ }^{6}$ The average allocation to a CDE any given year is close to $\$ 50$ million. While the NMTC program represents only a fraction of total spending and foregone taxes among federal community and economic development programs, it

\footnotetext{
${ }^{3}$ See the online appendix for additional details regarding the structure of the NMTC program.

${ }^{4}$ The original NMTC program was authorized to allocate $\$ 15$ billion between fiscal years 2002 and 2006. In subsequent years, the program has been amended and re-authorized a number of times.

${ }^{5}$ The information in this section is derived in large part from the CDFI Fund's website (www.cdfifund.gov), which outlines CDE eligibility requirements in detail and provides a list of current CDEs.

${ }^{6}$ Though originally scheduled to begin in fiscal 2002, no allocations were made until 2003 owing to delays in launching the program (U.S. Government Accountability Office 2007).
} 
has expanded over time and continues to grow both because more allocations have been made available by Congress and because tax credits from early rounds continue to be claimed.

Unlike the Low-Income Housing Tax Credit or the Community Development Block Grant programs, which leave decisions about the allocation of funds to states or localities, NMTC allocations flow directly from the federal government to CDEs. The CDEs that receive allocations are selected through a competitive application process, with less than one-fifth of applicants receiving allocations in any given year. ${ }^{7}$ Once a CDE is awarded a NMTC allocation, it has five years to use the proceeds of QEIs to provide equity or debt capital in the form of socalled qualified low-income community investments (QLICIs). ${ }^{8}$ As Figure 1 shows, as the amounts that the CDFI Fund allocated to CDEs generally rose over the course of the decade, QLICIs increased steadily until fiscal year 2008, at which point they slowed in the face of the recession. In 2009, however, investment under the program recovered. ${ }^{9}$

NMTC program rules dictate that "substantially all" of the investments made by CDEs go to designated low-income communities (LICs), but these investments can take a number of different forms. Over 85\% of QLICIs take the form of loans. However, since investors' returns are at least in part covered by the tax credit, CDEs have the flexibility to offer below-market interest rates or other preferential terms to qualified projects or businesses. Nonetheless, CDEs still have an incentive to assist viable projects with strong prospects. Indeed, there is some concern that the NMTC program crowds out private unsubsidized investment. Gurley-Calvez et al. (2009) argue that crowd out is not complete and that the NMTC program not only redirects investment dollars from higher income to lower income communities, but also increases the overall amount of resources available for investment in low-income areas. However, research on other place-based programs suggests that crowd out is a potentially large concern (Sinai and

\footnotetext{
${ }^{7}$ Applications to the CDFI Fund require CDEs to describe their intended use of the funds in four areas. Those areas include business strategy, capitalization strategy, management strategy, and community impact. Each of these areas is given a score by each member of a panel of CDFI reviewers that ranges from 0 to 25 . Extra points are also awarded if the applicant has a demonstrable history of serving disadvantaged communities or businesses, or if the NMTC plans to invest most of its capital in unrelated entities. Each reviewer tallies his or her own points and makes a recommendation of whether the CDE should receive funding and, if so, how much. CDFI staff then review the top proposals, and the NMTC program manager makes the final allocation determination (Rubin and Stankiewicz 2005).

${ }^{8} \mathrm{CDEs}$ may be for-profit or not-for-profit; the latter account for about one-fourth of CDEs that receive NMTC financing. However, to invest in eligible projects, a not-for-profit CDE must create a for-profit subsidiary.

${ }^{9}$ The QLICI data in the figure reflect reports to the CDFI Fund through December 2009. At $\$ 4.6$ billion, total fiscal year 2009 investment was about $20 \%$ higher than what is shown in the figure. Because the outcome data cover only through calendar year 2009, I do not consider any investment that occurs in calendar year 2010.
} 
Waldfogel 2005, Eriksen and Rosenthal 2010). I discuss the implications of crowd out for my analysis and present some suggestive evidence on the extent of crowd out in Section 7.

Over two-thirds of $\mathrm{CDE}$ investment has historically gone to commercial real estate development (70\% of all investment dollars through 2009). Commercial real estate projects are typically easier to pair with other tax incentives. Further, because they are fixed in place, real estate projects are unlikely to fall out of compliance with NMTC program rules (Lambie-Hanson 2008). Of the investment dollars not directed toward commercial real estate investment, most go to business development, which mainly constitutes loans to firms. Investments of this kind, which constitute about $26 \%$ of all NMTC investment dollars to date, are about half the size of commercial real estate investments on average. Meanwhile, only about half of a percent of NMTC funds go to residential real estate development, in part because the financing of residential rental property is not permitted under the NMTC. ${ }^{10}$ The remainder of the funds (about 4\%) largely goes toward financing CDE activities and loan purchases.

Through 2009, \$16 billion of QEI proceeds had been funneled to 3,278 QALICBs. ${ }^{11}$ The average amount of funding provided by a CDE to a QALICB through 2009 was about \$4.9 million, but this is skewed higher by several very large projects. The median investment was \$2.3 million. Relative to project costs, NMTC funding is often substantial. Using cost estimates reported by CDEs, NMTC financing covers well over one-third of project costs on average (U.S. Government Accountability Office 2010).

\subsection{Low-income communities}

In general, communities eligible for NMTC-subsidized investment through CDEs are census tracts that meet at least one of two criteria. Tracts outside metropolitan statistical areas (MSAs) with median family income (MFI) that does not exceed $80 \%$ of their state's MFI qualify for NMTC-subsidized investment, as do tracts in MSAs with MFI that does not exceed $80 \%$ of the greater of MSA MFI or statewide MFI. Tracts with poverty rates of at least $20 \%$ also qualify as LICs. A handful of "low-population" tracts also qualify; these tracts have populations less than 2,000, are located in Empowerment Zones, and are contiguous with another LIC. Finally, several

\footnotetext{
${ }^{10}$ Residential rental property is eligible for funding under the Low-Income Housing Tax Credit.

${ }^{11}$ Some QALICBs received multiple investments from CDEs. In total, 4,444 investments were made through 2009.
} 
"rural, high out-migration" tracts qualify; these tracts are located outside MSAs, have MFI less than or equal to $85 \%$ of statewide MFI, and have net out-migration of at least $10 \%$ of the population between 1980 and 2000. ${ }^{12}$

CDEs are also permitted to finance businesses outside of LICs as long as the businesses serve a targeted population, which constitutes "individuals, or an identified group of individuals, including an Indian tribe, who (a) are low-income persons; or (b) otherwise lack adequate access to loan or equity investments." ${ }^{13}$ In practice, LICs have received 95\% of NMTC investment dollars and $96 \%$ of NMTC projects. ${ }^{14}$

Of the 65,443 tracts in the 50 states and the District of Columbia, 39\% currently qualify as LICs. Of those that qualify, over $98 \%$ qualify either on the MFI ratio or the poverty rate criterion. Of those, $95 \%$ qualify on the MFI criterion; only 1,305 tracts qualify on the poverty rate criterion alone. ${ }^{15}$ Figure 2 shows tract LIC status as a function of its MFI ratio for all tracts with MFI between $50 \%$ and $110 \%$ of state or MSA MFI (the solid dots) and for only tracts with poverty rates less than $20 \%$ in the same 60 percentage point window (the hollow dots). Consistent with program rules, all tracts with MFI ratios less than 0.8 qualify as LICs and are eligible to receive NMTC-subsidized investment. Immediately above the 0.8 MFI ratio threshold, the fraction of tracts that are LICs drops sharply. In the full sample, only $10.8 \%$ of tracts with MFI ratios between 0.8 and 0.9 are LICs. ${ }^{16}$ Among tracts with poverty rates less than $20 \%$, only $4.9 \%$ of those with MFI ratios between 0.8 and 0.9 are LICs (a handful of low-population and rural, high out-migration tracts below the poverty rate cutoff and above the income cutoff qualify as LICs).

\footnotetext{
12 The NMTC and the Community Reinvestment Act (CRA), which aims to encourage commercial banks and savings institutions to assist in meeting the credit needs of lower-income communities, have similar, but not identical, formula structures. Census tracts in MSAs are designated underserved under the CRA if tract MFI is less than or equal to $80 \%$ of MSA MFI (as opposed to $80 \%$ of the maximum of statewide and MSA MFI). Census tracts outside of MSAs are designated underserved under the CRA if tract MFI is less than or equal to 80\% of nonmetropolitan state MFI (as opposed to state MFI more broadly defined). Hence, the income ratio used to determine CRA eligibility is always different than the income ratio used to determine NMTC eligibility status for tracts outside MSAs, and is different for $36 \%$ of tracts within MSAs. Further, not only are previous estimates of the magnitude of the CRA's effects on neighborhood outcomes modest (Gabriel and Rosenthal 2009, Bhutta 2010), but using CRA eligibility status (along with a flexible control function using the CRA income ratio) yields no significant results in a reduced-form regression analogous to equation (2).

${ }^{13}$ American Jobs Creation Act of 2004 (HR 4520).

${ }^{14}$ These figures exclude NMTC investment put toward financing CDE activities and loan purchases.

${ }^{15}$ Current designations are based on 2000 Decennial Census data and geographic boundaries. Beginning in mid2012, designations will be based on 2006-2010 American Community Survey data and boundaries.

${ }^{16}$ Because few tracts qualify on the poverty rate criterion alone, the discontinuity in eligibility is much smaller at the $20 \%$ poverty rate threshold. Nearly $70 \%$ of tracts with poverty rates greater than $15 \%$ but less than $20 \%$ are LICs.
} 
As I discuss in subsequent sections, as a result of the nonlinearity in eligibility at the MFI ratio cutoff, NMTC investment activity varies discontinuously at the 0.8 threshold, which allows me to credibly identify the effects of investment spurred by the NMTC on neighborhood outcomes.

\section{Empirical approach}

\subsection{Model}

This paper aims to identify the effects of investment subsidized by the NMTC on each of several neighborhood outcomes. I conduct the analysis at the level of census tract; tracts have populations that average 4,000 and are designed by the U.S. Census Bureau to approximate neighborhoods.

Following Chay and Greenstone (2005) and Baum-Snow and Marion (2009), I am interested in estimating $\beta_{1}$ in the following equation:

$$
\Delta y_{i}=\beta_{0}+\beta_{1} N_{i}+\mathbf{X}_{i} \Omega+\varepsilon_{i}
$$

In equation (1), $\Delta y_{i}$ denotes the change in outcome $y$ in tract $i$ (e.g., the change in the median home value or the poverty rate), $N_{i}$ denotes the amount of NMTC-subsidized investment in $i$, and $\mathbf{X}_{i}$ is a set of baseline (year 2000) tract characteristics. Estimating equation (1) on all tracts is unlikely to yield consistent estimates of $\beta_{1}$ given that unobserved and unmeasured local characteristics could affect both the amount of investment in a neighborhood and also be correlated with the outcome of interest. The decision of a CDE to allocate funds to a particular area is likely to be influenced by local characteristics as well as expectations about the future prospects of an area, each of which may not be fully captured in $\mathbf{X}_{i}$ and might also affect $\Delta y_{i}$. To the extent that we cannot control for such factors, the error term $\varepsilon_{i}$ will be correlated with the treatment $N_{i}$, which in turn will bias estimates of $\beta_{1}$.

In order to address the endogeneity problem, I adopt a regression discontinuity (RD) design that exploits the formula determining the eligibility of tracts for NMTC-subsidized funding from CDEs. In a RD framework, whether an observed covariate (i.e., the forcing variable) falls on one side of a fixed cutoff value or the other at least partly determines treatment. ${ }^{17}$ For the purposes of identifying the effects of NMTC-subsidized investment on outcomes, I focus on the ratio of tract MFI to state or MSA MFI (the greater of the two in MSAs) as the forcing variable. In general,

\footnotetext{
${ }^{17}$ For a detailed discussion of RD designs, see Lee and Lemieux (2010).
} 
tracts with MFI at or below $80 \%$ of the greater of MSA or statewide MFI are eligible for NMTCsubsidized investment, whereas similar tracts just above the $80 \%$ threshold are not. The discontinuity I use is fuzzy since a handful of tracts qualify as LICs on criteria other than the income ratio criterion. However, the vast majority of qualifying tracts are eligible based on the income ratio criterion. As Figure 2 shows, the fraction of tracts eligible for NMTC-subsidized investment falls sharply at the $0.8 \mathrm{MFI}$ ratio cutoff, indicative of the small number of tracts that qualify as LICs on the poverty rate criterion, the low-population criterion, or the rural high outmigration criterion and not on the income ratio criterion. ${ }^{18}$

The crucial assumption underlying my empirical strategy is that tracts in a sufficiently narrow window around the $80 \%$ income ratio are similar along observable dimensions and unobservable dimensions. More specifically, and as I verify in Section 4.3, covariates besides the treatment that might affect the outcomes of interest do not change discontinuously at the MFI ratio threshold for LIC qualification. Meanwhile, although some tracts that fail to satisfy the income criterion qualify as LICs and receive NMTC-subsidized investment, the probability of treatment changes sharply at the MFI threshold. In particular, as I show in Section 5.1, tracts just below the 0.8 cutoff are substantially more likely to receive investment subsidized by the NMTC than otherwise similar tracts just above the threshold. Given this, and that the association of other covariates with outcomes is smooth through the threshold, we can interpret any discontinuity in the conditional distribution of outcomes as a causal effect of the treatment.

For a population of tracts near the $80 \%$ income ratio, LIC designation is assigned essentially at random. To the extent that it only affects other outcomes through its effect on where subsidized investment is likely to take place, LIC status may act as an instrument for investment. The first-stage regression is therefore

$$
N_{i}=\alpha_{0}+\alpha_{1} L I C_{i}+f\left(m_{i}\right)+\mathbf{X}_{i} \Sigma+v_{i},
$$

where $L I C_{i}$ is a treatment indicator that takes a value of 1 if the tract is a LIC and 0 otherwise. The forcing variable $m_{i}$ denotes the ratio of tract MFI to the greater of MSA MFI or statewide MFI among tracts in MSAs, and the ratio of tract MFI to statewide MFI for tracts outside of MSAs. I use a variety of specifications for the control function $f$, though my preferred

\footnotetext{
${ }^{18}$ In Section 6.2.2, I exploit the multi-dimensionality of the discontinuity by limiting attention to only tracts with poverty rates less than $20 \%$. There are not a sufficient number of tracts that qualify on the poverty rate criterion alone to identify the effects using that cutoff.
} 
specifications use cubic and quartic polynomials in which the polynomial coefficients are permitted to differ above and below the cutoff. ${ }^{19}$ As I show in the results, the estimates vary little with different specifications of the control function. Further, as would be expected if the identification strategy outlined here is valid, the inclusion of controls in $\mathbf{X}$ does not affect the results substantially, although they tend to improve the precision of the estimates by reducing sampling variability.

The reduced-form relationship between LIC status and neighborhood outcomes is as follows:

$$
\Delta y_{i}=\gamma_{0}+\gamma_{1} L I C_{i}+f\left(m_{i}\right)+\mathbf{X}_{i} \Psi+u_{i} .
$$

Since the model is just-identified, the IV estimate of $\beta_{1}$ is simply the ratio of the estimates of $\gamma_{1}$ and $\alpha_{1}$ from the reduced-form and first-stage regressions, respectively.

\subsection{Identification}

The critical identifying assumption underlying the $\mathrm{RD}$ design used in this paper is that unobservable determinants of $\Delta y_{i}$ do not differ among tracts within a narrow window on either side of the cutoff. One potential threat to this assumption is that sorting occurred among neighborhoods around the threshold. Although selection into treatment is often a problem in the analysis of EZs, it is highly unlikely that sorting occurred in the case of the NMTC. The 2003 designations I use are based on data from the 2000 Decennial Census, which was conducted before the NMTC legislation was even signed into law. Even if officials anticipated the formula structure of the NMTC and attempted to influence the returns from the census accordingly, it is technically only necessary that they did not have perfect control over the forcing variable (Lee 2008). It is doubtful that any official had the ability to determine with pinpoint accuracy the value of the forcing variable for any given tract; the sampling variability associated with the onein-six sample drawn for the long-form Decennial Census, as well as imputation and confidentiality protection procedures conducted by the Census, add some degree of noise to the data that would have to be predicted by local officials. These factors militate against any unobserved sorting around the threshold that might invalidate the RD design. As further checks

\footnotetext{
${ }^{19}$ Specifically, I use control functions that take the following general form:

$$
f\left(m_{i}\right)=\sum_{k=1}^{p}\left[\varphi_{1 k}\left(m_{i}-0.8\right)^{k}+\varphi_{2 k} L I C_{i}\left(m_{i}-0.8\right)^{k}\right]
$$

where $p$ is the order of the polynomial.
} 
that no sorting has occurred around the cutoff, in Section 4.3 I provide descriptive evidence and test formally that there is no discontinuity in the distribution of the forcing variable at the cutoff and that observable baseline covariates evolve smoothly through the threshold.

Notably, the fuzzy RD design provides a weighted average of the effects of the treatment for the subpopulation of neighborhoods near the cutoff that receive investment, with weights proportional to the ex-ante likelihood of having a MFI ratio near the threshold. It is unlikely that the treatment effect is homogenous across all neighborhoods, and hence it would be misguided to assume that the estimated effects would be similar in very high income or very low income neighborhoods far from the threshold. The lack of external validity is a common feature of RD designs, but it does not imply that the estimates in this paper are not of interest. Indeed, the local average treatment effect that I identify is of critical importance to understanding how the NMTC program spurs investment, and how this investment affects disadvantaged (albeit not extremely poor) communities (i.e., those tracts with MFI near $80 \%$ of the MSA or state MFI).

\section{Data}

\subsection{Data sources}

The data used in this analysis come from several sources. The first is the CDFI Fund at the U.S. Treasury. The CDFI Fund provided data on all CDE investments, including the amount of the investment (including total project cost and NMTC funding), the type of investment (commercial real estate, business development, etc.), and the location of the investment (street address). Using commercial GIS software, I assigned each investment to a census tract. These data were then merged with information at the tract level on LIC eligibility, which is derived from 2000 Decennial Census data.

Baseline resident characteristics of tracts were taken from the 2000 Decennial Census. These data include a number of demographic characteristics, including total population, racial and ethnic composition, the age distribution, educational attainment levels, household size, household and family income, poverty rates, and unemployment rates. The data also contain a host of tract housing characteristics, including total housing units, share vacant, share occupied, share owned, share rented, share with a mortgage, median age of units, median number of rooms per unit, household turnover, and median house value. 
In order to examine how neighborhoods changed over the course of the 2000s, I use smallarea American Community Survey (ACS) estimates for 2005-2009. These data are based on interviews conducted by the Census Bureau over a five-year period in the second half of the decade. These data do not measure neighborhood characteristics in a given area in a particular year, but instead measure average neighborhood characteristics over the entire five-year period. The geographic boundaries in the 2005-2009 ACS largely match those used in the 2000 Decennial Census. ${ }^{20}$ I extract from the ACS information on house values, household income, poverty rates, unemployment rates, and household turnover at the tract level.

The neighborhood outcomes of interest are measured as changes between 2000 and 20052009. To the extent that NMTC-subsidized projects take place later in the decade or take some time to have an impact on neighborhood conditions, these outcome measures may not fully capture their effects and the IV estimates presented in subsequent sections should be scaled up. In other words, the overlap in the period during which we observe outcomes and the period in which investment occurs may introduce a degree of measurement error that will tend to bias me toward finding no effects of investment on neighborhood conditions.

The Decennial Census and ACS are each survey-based and provide information on the demographic and economic characteristics of tract residents. To the extent that the intent of the NMTC program was to revitalize blighted communities, the effects of investment subsidized by the program on tract residents are of particular policy interest. Also important, however, are the effects on commercial activity in affected areas. Ideally, one would have information on all subsidized and unsubsidized commercial real estate investment, business loans, and job growth for all tracts, in which case one could quantify the cumulative effect of subsidized investment on economic activity as well as the amount of crowd out associated with the program.

While I do not have data on all commercial real estate investment and loans for all tracts, I obtained administrative data on total employment and the composition of jobs within tracts from the Longitudinal Employer-Household Dynamics (LEHD) program at the Census Bureau. ${ }^{21}$

\footnotetext{
${ }^{20}$ There were several exceptions. After 2000, changes in county or county equivalents occurred in Virginia, Colorado, and Alaska. Additionally, nine states used 2010 Census boundaries for census tracts in the ACS. I normalized all geography to 2000 using crosswalks provided by the Census.

${ }^{21}$ These data are derived from LEHD's OnTheMap program, which provides annual cross-sectional information on jobs at detailed geographies. I include in the sample only private primary jobs; a primary job represents the highest paying job for each worker in each year. This eliminates from the sample many low-earnings, transient jobs
} 
These data, which are derived from state unemployment insurance records and cover over $98 \%$ of private sector employment, contain job counts as well as pay categories (fraction of jobs paying less than $\$ 15,000$ annually, fraction of jobs paying between $\$ 15,000$ and $\$ 39,999$ annually, and fraction of jobs paying $\$ 40,000$ or more annually). ${ }^{22}$ While these data are only available for 2002-2009 and only for 45 states, ${ }^{23}$ they allow me to test directly for the impact of subsidized investment on the number of jobs and the types of jobs available within affected communities. In turn, while I cannot quantify the total amount of crowd out associated with the program, I can shed some light on whether subsidized investment is generating more or better jobs. To the extent that there is differentially greater job growth or a shift toward better paying jobs in communities that receive subsidized investment, it would suggest that if there is crowd out of unsubsidized investment, it is not complete.

\subsection{Summary statistics}

Excluding those in Gulf Opportunity (GO) Zones ${ }^{24}$ or in tracts with missing information in either the 2000 Decennial Census or the 2005-2009 ACS, QLICIs between 2003 and 2009 were distributed across 488 counties and 1,538 tracts in the U.S. ${ }^{25}$ Table 1 characterizes the differences between tracts that received projects and those that did not. Columns (1) and (2) include all tracts, while columns (3) and (4) include only tracts designated as LICs. Every tract in the latter sample is eligible for NMTC-subsidized investment, but only a subset received any

and allows for a closer comparison to past work on the employment effects of EZs. The results are qualitatively and quantitatively similar if one uses all private-sector jobs. See Andersson et al. (2008) for details regarding the data.

${ }^{22}$ These thresholds are not adjusted for inflation each year, and hence there is a gradually declining fraction of jobs in the low-earnings bin and a gradually increasing fraction of jobs in the high-earnings bin. In the empirical analysis, I test for whether tracts that received subsidized investment experienced differentially large or small changes in the shares.

${ }^{23}$ Arizona, Arkansas, DC, Massachusetts, Mississippi, and New Hampshire are excluded because they did not provide data to the LEHD program one or more years between 2002 and 2009. Notably, because the LEHD data are available each year, the results using them are not subject to the same timing problems associated with results using the 2005-2009 ACS.

${ }^{24}$ About two-thirds of tracts in Louisiana and Mississippi and one-fifth of tracts in Alabama (a total of 1,403 tracts) were designated part of the GO Zone. Developments in these areas were given special preference in the wake of Hurricane Katrina. Including these tracts in the sample has little effect the findings overall, but results in a weaker first-stage and affects the precision of some of the estimates.

${ }^{25}$ These exclude loan purchases by CDEs. Note that I use the date that CDEs report using the proceeds of QEIs to make QLICIs as opposed to the date that the CDFI Fund reports allocating credits to CDEs. Once awarded credits, CDEs have up to five years to use the proceeds of QEIs to make investments, and therefore actual investments, much less their impacts on neighborhoods, could take some time to materialize. 
investment through $2009 .{ }^{26}$ The first two columns of Table 1 make clear that, as would be expected given LIC eligibility requirements, tracts that received investment were more disadvantaged than the typical tract in the U.S in terms of baseline demographic characteristics (Panel A) and housing characteristics (Panel B). Educational attainment levels, income levels, home values, vacancy rates, and other indicators of disadvantage were consistently worse in 2000 in tracts that received investment later in the decade.

However, columns (3) and (4) of Table 1 suggest that among tracts designated as LICs, those that received investment were comparable along most observable dimensions to those that did not. Racial composition and educational attainment levels, for example, were very similar. Not surprisingly given that a disproportionate amount of NMTC-subsidized investment occurs in urban areas, the share of renter occupied units as well as median home values are somewhat greater on average in LICs that receive investment.

In Panel C of Table 1, I also present average values of the main outcome variables of interest, including average changes between 2000 and 2005-2009 in log median home values, log median household income, poverty rates (measured in percentage points), unemployment rates (measured in percentage points), and the percentage of households in a different residence than one year ago (measured in percentage points and labeled household turnover). Even in the unconditional means of the outcomes reported in columns (3) and (4), there is some suggestive evidence of relative improvement in LICs that received NMTC-subsidized investment. For instance, home values increased more and poverty rates and unemployment rates increased less in LICs that received investment compared to those that did not. However, comparisons only among LICs could be biased by unobservable neighborhood characteristics correlated with NMTC-subsidized investment and with outcomes. The RD design outlined in the previous section aims to address this problem by comparing only tracts in a narrow window around the 0.8 MFI ratio cutoff, where LIC status can be thought of as randomly assigned to tracts.

\subsection{RD sample}

For the RD design to be valid, a sufficiently narrow window around the relevant threshold must be used to ensure that observations on either side are similar along both observable and

\footnotetext{
${ }^{26}$ The number of tracts in column (3) is less than in column (1) because, as discussed in Section 2.2, a small amount of subsidized investment occurs outside LICs.
} 
unobservable dimensions. In the main analysis, I limit attention to census tracts with MFI ratios (based on 2000 Decennial data) between 0.7 and 0.9 (inclusive). The final sample of tracts in the U.S. (excluding Puerto Rico) with all requisite variables available and that are not in GO Zones is 17,271 tracts. ${ }^{27}$ As robustness checks, I consider alternative windows around the 0.8 threshold as well as placebo cutoffs.

In Figure 3, I plot the number of tracts in each half percentage point bin of the MFI ratio in a 60 percentage point window around the 0.8 cutoff that largely determines eligibility for NMTCsubsidized investment. The shaded region constitutes the main sample of tracts used the analysis. While there is a large concentration of tracts near the threshold, there is no indication of a discontinuity in the density of the forcing variable at the cutoff. A McCrary (2008) test confirms there is no statistically significant jump in the density function at 0.8 . This is consistent with a lack of any manipulation in the value of the MFI ratio that might undermine the RD design.

Table 2 presents descriptive statistics for census tracts in the main sample. In Panels A and B, average values for the baseline demographic and housing variables are presented in bins of the forcing variable on either side of the 0.8 threshold. There is little evidence that the covariates are anything but smooth through the cutoff. Consistent with the density test of the forcing variable itself, tests of the null hypothesis of continuity of the density of each of the covariates, as well as that of the initial (i.e., year 2000) values of the outcome variables, against the alternative of a jump in the density suggest that there is no sorting around the threshold. ${ }^{28}$

For the analysis, I sum up the total dollar amount of NMTC-subsidized investment and the number of NMTC-subsidized projects for each tract over 2003-2009. Panel C of Table 2 shows average levels of NMTC-subsidized investment and projects within each bin on either side of the threshold. In contrast to the baseline characteristics presented in panels A and B, there is clear evidence of greater NMTC activity immediately below the threshold relative to immediately above the threshold. I focus in on the spatial patterns of development in the next section.

\footnotetext{
${ }^{27}$ Due to missing data for five states and DC, I lose an additional 895 observations in the LEHD sample. I also drop from the LEHD sample 209 tracts that have fewer than 20 jobs in either 2002 or 2009 due to cell suppression affecting mainly lower population tracts that contributed to implausibly large percentage changes in employment over the period. The results are qualitatively similar, but even less precise with the inclusion of these outliers.

${ }^{28}$ Graphical evidence of the lack of discontinuities in the baseline covariates is presented in the online appendix.
} 


\section{NMTC-subsidized investment}

\subsection{Investment location estimates}

First, I present graphical evidence on the effects of LIC status on NMTC-subsidized investment in tracts between 2003 and 2009. Figure 4 plots predicted values of each of the two outcome variables, total NMTC-subsidized investment (Panel A) and NMTC-subsidized projects (Panel B), using various control functions (linear, quadratic, and cubic) as well as average values of each of the two variables within half percentage point bins of the forcing variable. ${ }^{29}$ There are conspicuous discontinuities at the cutoff, with sharp drops in both the total amount of NMTCsubsidized investment and the number of projects on average within each bin above the 0.8 cutoff. While substantially lower, investment in neighborhoods above the threshold is not zero; as Figure 2 suggests, a small number of tracts with MFI ratios above 0.8 qualify on other criteria and are also eligible for NMTC investment. However, it is clear that there is a discrete increase in the probability of receiving investment for projects just below the 0.8 income ratio cutoff.

Corresponding regression estimates of the discontinuities in NMTC-subsidized investment and projects appear in Panel A of Table 3. Each cell reports an estimate of $\alpha_{1}$ for a different specification of equation (2), including specifications with different functional forms for $f$ and with different sets of controls in $\mathbf{X}$. The tracts included in the sample have MFI ratios between 0.7 and 0.9. The first row of coefficients in Panel A shows the estimated effects of LIC status on NMTC-subsidized investment between 2003 and 2009, while the second row shows the effects of LIC status on the number of NMTC-subsidized projects between 2003 and 2009. Columns (1) and (4) include only cubic and quartic control functions, respectively. The intervening columns include additional local demographic and housing market controls as explanatory variables. All regressions include county dummies, and I allow for arbitrary correlation in errors within counties by clustering the standard errors in each regression at the county level.

Consistent with the discontinuity gap in Panel A of Figure 4, the first row of Table 3 indicates that LICs receive on average about \$1 million more in NMTC-subsidized investment than similar neighborhoods that are not LICs. The results are not highly sensitive to the particular specification of the control function or set of covariates included; the estimated effects range from $\$ 859,000$ to $\$ 1,110,000$. All the estimated coefficients are significant at least at the $1 \%$

\footnotetext{
${ }^{29}$ Figures with varying sized bins appear in the online appendix.
} 
level. The second row shows that LICs receive on average 0.04 QALICBs; again, the effects are precisely estimated and vary little across the different specifications. ${ }^{30,31}$

\subsection{Placebo Estimates}

To verify that the observed jumps are in fact being driven by the LIC eligibility threshold, I carry out two tests. First, I conduct a placebo exercise using a series of alternative thresholds. The results of this robustness check appear in Figure 5, in which I plot discontinuity estimates from separate regressions run using 20 percentage point windows around each percentage point between 0.7 and 0.9. I present results from regressions including a cubic polynomial in the MFI ratio around the false threshold and the full set of controls. ${ }^{32}$ Due to small sample sizes, the estimates tend to be noisier and more volatile for placebo cutoffs at the lower end of the tract income distribution. Importantly and as expected, though, except for at the actual cutoff of 0.8 , the estimated discontinuity gaps are always statistically indistinguishable from zero.

As a second placebo test, I examine whether there is any evidence of a discontinuity at the 0.8 MFI ratio cutoff using only tracts with poverty rates greater than or equal to $20 \%$. Conditional on having a poverty rate at or above $20 \%$, we would not expect to see any discontinuity in NMTC activity at the 0.8 MFI ratio cutoff. In Figure 6, I plot average NMTCsubsidized investment and projects in half percentage point bins within a 20 percentage point window around the 0.8 MFI ratio cutoff using only a sample of high poverty tracts. As expected, there is NMTC activity on both sides of the 0.8 cutoff and little evidence of any discontinuity at the MFI ratio threshold. ${ }^{33}$

\footnotetext{
${ }^{30}$ The first-stage regressions reported in Panel A of Table 3 pass standard weak instrument tests (Staiger and Stock 1997). Kleibergen-Paap test statistics, which are robust to heteroskedasticity, fall between 10.6 and 11.5 for the estimates in columns (1)-(6) of the first row of Table 3 (which constitute the first-stages for the main IV results). Weak instruments would tend to bias the IV estimates (reported in the next section) upward in absolute value. However, weak-instrument robust confidence intervals based on the Anderson-Rubin test (Anderson and Rubin 1949, Moreira 2009) corroborate the main results.

${ }^{31}$ Given the lack of independent exogenous variation in each type of investment, I am limited in my ability to investigate the potentially differential effects of real estate projects and business development projects on neighborhoods. However, in the online appendix, I explore the extent to which the NMTC program seems to favor different types of investment.

${ }^{32}$ Figures with different specifications of the control function and different sets of controls look very similar.

${ }^{33}$ In the online appendix, I also show that there is little evidence of discontinuities in outcomes at the 0.8 MFI ratio cutoff for the subsample of tracts with poverty rates greater than or equal to $20 \%$.
} 
The results of these placebo tests, together with Figure 4, suggest that the observed jump at 0.8 is not an artifact of the data, but rather is a real effect driven by the formula structure of the NMTC program.

\section{The effects of NMTC-subsidized investment on housing and resident characteristics}

Congress established the NMTC as part of an effort to revitalize blighted communities. The belief was that, by encouraging private investment in neighborhoods in which access to capital through traditional channels might be limited, the NMTC could inject new life into stagnant lowincome communities (U.S. Government Accountability Office 2007). Not only might the fresh investment in real estate projects and operating businesses facilitated by the NMTC generate new jobs, but it might eliminate vacant lots and abandoned buildings as well as generate other positive externalities. To the extent that these benefits arise, they should be capitalized into local home values. Also, new investment, and any accompanying revitalization of neighborhoods, could affect the economic conditions of existing residents as well as change the composition of residents in an area. I explore the effects of NMTC-subsidized investment on housing and resident characteristics in this section before examining its effects on employment in Section 7.

\subsection{Main results}

I begin by investigating the relationship between NMTC-subsidized investment and changes in housing and resident characteristics at the tract level between 2000 and 2005-2009. Panel A in Table 4 presents OLS estimates of $\beta_{1}$ in equation (1), with the change in log median house value, the change in log median household income, the change in the poverty rate (measured in percentage points), the change in the unemployment rate (measured in percentage points), and the change in the percentage of households that lived in a different residence one year ago (measured in percentage points and labeled household turnover) as the outcome variables. ${ }^{34} \mathrm{I}$ examine how each of these outcomes correlates with the amount of NMTC-subsidized investment (in millions of dollars). ${ }^{35}$ For brevity, I present only results using third-order

\footnotetext{
${ }^{34}$ I consider changes in each of the outcome variables for consistency and ease of interpretation. Results using levels in the outcome years are qualitatively similar.

${ }^{35}$ Given that project size varies substantially and that we would generally expect more expensive projects to have larger impacts on communities, I focus on investment dollars rather than number of projects. The results are qualitatively similar when I instead use number of projects.
} 
polynomial and fourth-order polynomial forms of the control function, but show estimates from specifications with no other covariates, with only the control function and demographic covariates, and with the control function and demographic and housing covariates. All regressions include county dummies, such that the relationships between NMTC-subsidized investment and outcomes are identified off variation across tracts within counties. ${ }^{36}$ Standard errors, which appear below the coefficients in parentheses, are clustered at the county level.

The OLS estimates suggest that there are small and generally insignificant relationships between NMTC-subsidized investment and each outcome. The estimates in the first row of Panel A in Table 4 imply that, regardless of the particular set of controls used, receiving \$1 million in NMTC-subsidized investment is associated with a 0.01-0.03\% decrease in median home values at the tract level. The relationship between investment and median household income is positive, but also small in magnitude; receiving \$1 million in NMTC-subsidized investment is associated with a $0.02 \%$ increase in median household income. There is some indication that investment is negatively associated with poverty and unemployment rates, but the coefficient estimates are generally insignificant and economically trivial in magnitude. Indeed, differences in unemployment rates among low-income tracts that do and do not receive $\$ 1$ million in investment are less than a tenth of a percentage point on average. In the final row of Panel A, there is some indication that tracts that receive investment experience more household turnover, but the estimated relationship is weak. Taken alone, these results might be interpreted as evidence that subsidizing the financing of commercial real estate investment and business development in low-income neighborhoods does little to encourage revitalization.

However, the OLS estimates may be biased by unobserved factors that are correlated with NMTC-subsidized investment and also affect the outcomes of interest. Panel B in Table 4 presents analogous results from a fuzzy RD approach in which I instrument NMTC-subsidized investment with an indicator for LIC status. Again, the assumption is that LIC status only affects the outcomes through its effect on where investment occurs. As shown in the previous section, LIC status is strongly predictive of the locations of NMTC-subsidized investment by CDEs.

\footnotetext{
${ }^{36}$ As I discuss in Section 6.3, the results are qualitatively similar without county effects. The results are also similar when one weights the estimates by tract population, which is not surprising given that the Census Bureau defines tracts in a manner that ensures that all have close to 4,000 residents.
} 
The IV estimates are an order of magnitude larger than the OLS estimates. However, the standard errors, again clustered at the county level, are also larger; as a result, many of the estimates remain statistically indistinguishable from zero. ${ }^{37}$ The results for changes in median home values in the first row of Panel B in Table 4 indicate that \$1 million in NMTC-subsidized investment leads to a roughly $2 \%$ increase in median home values at the tract level. With a pvalue of 0.15 , the estimate from the preferred specification in column (3) is close to statistically significant. Although median household income appears unaffected, \$1 million in NMTCsubsidized investment reduces poverty rates by about one percentage point off a base of $13 \%$, or by about $8 \%$. Meanwhile, unemployment rates in tracts that receive $\$ 1$ million in investment fall by about a third of a percentage point off a base of $6 \%$. Finally, household turnover rates increase by about three fourths of a percentage point in tracts that receive \$1 million in NMTCsubsidized investment (off a base of 16\%). This suggests that the observed changes in neighborhood characteristics are not entirely driven by improvements in the circumstances of existing residents, but instead are at least in part attributable to changes in neighborhood composition in the wake of new investment. ${ }^{38}$

The fact that the IV estimates are considerably larger than the OLS estimates may indicate that treatment is endogenous. The difference in estimated effect sizes could also reflect the fact that the IV estimates are local; the fuzzy RD design generates estimates of the average effect of the treatment for only those neighborhoods near the cutoff that receive NMTC-subsidized investment. These estimates may not generalize to a broader sample of neighborhoods.

Overall, the IV results are consistent with research on other place-based programs showing that subsidized development has positive effects on nearby home values and other neighborhood characteristics (e.g., Baum-Snow and Marion 2009, Freedman and Owens 2011). The results are also in line with recent findings that suggest that the provision of local subsidies to attract investments is worthwhile under some circumstances (Greenstone and Moretti 2004). The magnitude of the estimated effects of NMTC-subsidized investment, however, is consistent with

\footnotetext{
${ }^{37}$ Notably, adding covariates has only modest effects on the estimated standard errors. The stability of the estimates, though, helps to establish the validity of the RD design in this setting. For each of the outcomes, we cannot reject the null that the coefficients are the same across specifications.

${ }^{38}$ Results using only tracts in MSAs, which receive $80 \%$ of NMTC-subsidized investment, are qualitatively and quantitatively similar to the results for the full sample. Controlling for pre-treatment trends also has little effect on the main results. See the online appendix for details.
} 
much of the past work on state EZs, which point to relatively small impacts of business tax incentives on economic activity (e.g., Neumark and Kolko 2010). Indeed, the results suggest that to the extent that there are benefits associated with subsidizing investment in poor areas, those benefits are limited, and for many outcomes we cannot rule out that there is no effect at all. One exception is for poverty rates, where the estimates suggest that reducing by one the number of people in poverty in low-income tracts near the 0.8 MFI ratio cutoff over an approximately seven-year period requires roughly $\$ 23,500$ in NMTC-subsidized investment. ${ }^{39}$ By comparison, the $\$ 49.7$ billion in Earned Income Tax Credit (EITC) spending in 2007 raised some 4.0 million people out of poverty, implying that the federal government spent about $\$ 12,400$ per person lifted out of poverty under the tax credit program (Meyer 2010). However, direct cost comparisons are complicated by several factors. First, I estimate the effects of NMTC-subsidized investment on poverty only for tracts near the 0.8 MFI ratio cutoff; reducing poverty with subsidized investment may be more or less expensive in tracts far from the threshold. Second, to the extent that NMTC-subsidized investment generates externalities in neighborhoods that income maintenance programs like the EITC that are tied to people as opposed to places do not, comparing costs only in terms of the poverty or income of residents may not be justified. Finally, if NMTC-subsidized investment results in any reduction in poverty in affected neighborhoods by displacing low-income households or attracting higher-income households, the cost of improving conditions for poor individuals on aggregate may be much greater than the estimates suggest. The observed increase in the fraction of households that changed houses recently in the wake of new investment suggests that household turnover may indeed be an important means by which observed changes in poverty and other neighborhood conditions arise.

\subsection{Specification tests and robustness}

\subsubsection{Varying the window around the threshold}

To determine whether the particular window around the threshold chosen affects the main results, I re-ran each regression in Table 4 for a number of different bandwidths. For windows around the threshold as large as 60 percentage points and as small as ten, the OLS and IV results,

\footnotetext{
${ }^{39}$ Given that the average population of treated tracts in the sample is 4,261 and that poverty in those tracts fell by one percentage point in response to $\$ 1$ million in NMTC-subsidized investment, it requires $1,000,000 /(0.01 * 4,261)$ $=\$ 23,500$ to reduce by 1 the number of people in poverty in a low-income tract near the 0.8 MFI ratio threshold under the program.
} 
which appear in the online appendix, are qualitatively and quantitatively similar to those discussed in the previous section. For example, regardless of the particular window chosen, the IV estimates suggest that $\$ 1$ million in NMTC-subsidized investment in a tract translates into a borderline significant $1-2 \%$ increase in median home values. Meanwhile, notwithstanding the window used, poverty rates are consistently estimated to be significantly lower in tracts that receive subsidized investment relative to those that do not. The particular window chosen also does not affect the previous conclusions regarding median household income, the unemployment rate, or household turnover. The stability of the estimates across different windows suggests that the particular choice of bandwidth is not driving the main results.

\subsubsection{Exploiting the dual thresholds}

As previously discussed, areas eligible for NMTC-subsidized investment are determined largely as a function of the MFI ratio and the poverty rate. Since only about $5 \%$ of tracts qualify as LICs on the poverty rate criterion alone, I ignore those tracts in the previous analyses. As a check on the sensitivity of the results to this choice, I run the analysis on the subsample of tracts with poverty rates in 2000 less than $20 \%{ }^{40}$ Except for a small number of tracts that qualify on the low population or high out-migration criteria, those tracts in this subsample must qualify on the MFI criteria alone. As a result, as Figure 2 shows, the fraction of tracts immediately above the $0.8 \mathrm{MFI}$ ratio cutoff that qualify as LICs is lower in this "low poverty" sample relative to the main sample. While conducting the analysis for this limited group of tracts reduces the sample size and thus the precision of the estimates, it provides for a cleaner discontinuity in NMTC activity to exploit to identify the effects of interest. ${ }^{41}$

IV estimates of the effects of NMTC-subsidized investment for the subsample of tracts with poverty rates less than $20 \%$ appear in Table 5. The coefficient estimates are qualitatively similar to the main results for all tracts near the $80 \%$ MFI ratio cutoff. The effects of NMTC-subsidized investment on home values are positive but still statistically indistinguishable from zero. The

\footnotetext{
${ }^{40}$ This approach is similar to those of Jacob and Lefgren (2004) and Matsudaira (2008), who also have multiple forcing variables and limit attention to units that do not qualify on one cutoff to identify the effects of qualifying on the other. In the present context, since very few tracts qualify on the poverty rate criterion alone, it is not possible to restrict the sample to tracts that do not qualify on the MFI ratio criterion and identify the effects on the poverty rate frontier.

${ }^{41}$ See the online appendix for figures showing the discontinuity in NMTC-investment around the threshold for the subsample of tracts with poverty rates in 2000 less than $20 \%$.
} 
effect on the unemployment rate in the low-poverty sample is very similar to that reported for the full sample in Table 4, but the decline in poverty rates in response to investment is more muted.

That there are some differences in effect sizes between Tables 4 and 5 is not surprising, as it is merely a reflection of the local nature of the estimates and heterogeneous treatment effects. Tracts qualifying on the poverty rate criterion tend to be more densely populated urban areas with greater shares of younger residents, minorities, and renters. Excluding these areas generally yields smaller estimated effects of NMTC-subsidized investment on the characteristics and composition of residents in affected neighborhoods.

\subsection{Spillovers}

Neighborhoods eligible for NMTC-subsidized investment could attract businesses that would otherwise locate in other nearby areas. On the other hand, the benefits from NMTC-subsidized investment could spill over into surrounding areas. Specifications that use neighborhoods not designated as LICs that are geographically close to LICs as controls will tend to bias any estimated effects of subsidized investment on neighborhoods upward in absolute value in the former case and downward in the latter case.

To determine if and how spillovers affect the estimates, I conduct a series of additional robustness tests. First, I run regressions in which I replace the county effects with state effects. In regressions with county dummies, outcomes in treated tracts are compared to outcomes to similar control tracts in the same county. In regressions with state as opposed to county dummies, outcomes in treated tracts are compared to outcomes in similar control tracts throughout the state. The former approach, which is that used in the previous sections, helps to control for unobserved characteristics of counties that could be correlated with treatment and affect outcomes, but could amplify any bias attributable to spillovers. As the first two columns of Table 6 show, however, results with state effects are quite similar to those with county effects (the analogous columns are (1) and (3) in Panel B of Table 4). The estimated effect sizes in the IV regressions are somewhat smaller in magnitude for some outcomes (e.g., home values), but are the same size or slightly larger for others (e.g., poverty rates, unemployment rates, and household turnover). Overall, though, the similarity in results suggests that any bias owing to spillovers is unlikely to be large. 
However, low-income neighborhoods tend to be concentrated within states, and even without county effects, treated and control tracts are likely to be proximal. Therefore, in two additional tests, I use as controls tracts only drawn from counties that have no LICs and tracts that do not share a border with an LIC. The results of these two tests appear in columns (3)-(6) of Table 6. The results are qualitatively similar to the baseline IV results in Table 4, again suggesting that to the extent that there are spillovers to nearby neighborhoods, they are not sufficiently large as to affect the main conclusions. Notably, though, the variability in estimates across specifications in Table 6 with and without other covariates suggests that using more distant tracts as controls may introduce some omitted variable bias.

Of course, the fact that spatial spillovers are not substantially biasing my previous estimates does not necessarily mean that there are no spatial spillovers. However, given that $72 \%$ of tracts with MFI ratios between 0.8 and 0.9 share borders with LICs, the results in Table 6 suggest that spillovers are unlikely to be large. Prior evidence on spatial spillovers associated with geographically targeted incentive programs is mixed; while some studies point to sizable negative spillovers (Chirinko and Wilson 2008), other studies find little or no spillovers. For example, also using tracts as the unit of analysis, Ham et al. (2011) find positive but statistically insignificant spillovers of state and federal zone programs on neighboring areas.

Notably, even if the NMTC merely reallocates business investment from higher income to lower income neighborhoods without generating any new investment, it does not immediately imply that the program is not worthwhile. To the extent that there are positive externalities to new investment that are larger in lower income communities than in higher income communities, there is some argument to be made that the government should attempt to redirect some investment into poorer areas. On the other hand, if most of the money is funding investments that would have occurred in low-income neighborhoods regardless of the program, it would represent a more significant concern. I discuss the issue of crowd out in more detail in the next section.

\section{Crowd out and employment effects}

A major concern regarding the NMTC is that funds may be allocated to projects that would have received financing regardless. A direct test of the extent of crowd out, which has been significant in place-based housing programs (Sinai and Waldfogel 2005, Eriksen and Rosenthal 
2010), would require data not only on NMTC-subsidized business investment and commercial real estate transactions, but all business investment and commercial real estate transactions. The lack of a discontinuity in these indicators at the LIC threshold would indicate that the program is having little effect on overall business activity.

I do not attempt to quantify the precise amount of crowd out associated with the NMTC in this paper due to the lack of such expansive and detailed data. However, to the extent that there is crowd out of unsubsidized investment, one would expect to find little to no effect of NMTCsubsidized investment on housing and resident characteristics. Yet as discussed in the previous section, there is some indication that subsidized investment has positive, albeit small, effects on neighborhood conditions. Though still merely suggestive, a change in total employment and the composition of jobs in an area in response to new investment would provide more compelling evidence that the NMTC program is not merely crowding out private unsubsidized investment.

Using LEHD data for 45 states between 2002 and 2009, I exploit the discontinuity generated by the rule determining LIC status to test whether investment subsidized by the NMTC program between those years affected the total number of private-sector jobs and the composition of those jobs within tracts. Finding a positive effect on employment and the quality of jobs (in this case measured by earnings) would help to rationalize some of the findings with respect to home values, poverty, and unemployment. On the other hand, the finding of no effect on employment or the types of jobs in a community would not be entirely inconsistent with the previous results for neighborhood residents; even if they do not create new jobs, to the extent that NMTCsubsidized investments have amenity effects (e.g., by tearing down abandoned properties) or attract relatively affluent people to an area, they could have positive implications for resident survey-based measures of neighborhood conditions.

I present IV results using the LEHD data in Table 7. The results in the first row suggest that investment subsidized under the NMTC program has a modest positive effect on private-sector employment. Although imprecisely estimated, the estimates suggest that $\$ 1$ million in investment increases the number of private-sector jobs in a relatively poor tract by about $1-2 \%$. For tracts near the cutoff, which on average have about 1,320 private-sector jobs, that translates into roughly 20 jobs, each coming at a cost of approximately $\$ 50,000$. This is consistent with cost estimates from other place-based programs aimed at fostering business activity in distressed 
areas; recent research has suggested that the cost of creating a job under state EZ programs and federal Empowerment Zones and Enterprise Communities programs is in the range of $\$ 20,000$ to $\$ 100,000$ (Glaeser and Gottlieb 2008). Notably, though, while the job counts exclude secondary jobs, there is no restriction on earnings or hours on the primary jobs included in the sample. ${ }^{42}$ Hence, the cost per full-time equivalent job is likely well above $\$ 50,000$.

The results in Table 7 also show that NMTC investment is associated with a reduction in the share of jobs that pay less than $\$ 15,000$ annually and a commensurate increase in the share of jobs paying $\$ 15,000$ annually or more. Though there was a rightward shift in the distribution of earnings across tracts over the time period considered, the shift was more pronounced in tracts that received NMTC-subsidized investment. This suggests that, to the extent that subsidized investment generated jobs, those jobs tended to be higher quality jobs on average. These results are consistent with Busso et al. (2011), who find modest increases in wages among workers in federal urban Empowerment Zones. Nonetheless, the changes in shares of jobs in each pay category in response to new investment are not large, and in general, we cannot rule out that investment had no effect on average job quality. However, the pattern that emerges from these results and those results in the previous section suggests that, even though the program is relatively new and many of its projects might still be taking root, there may be some positive impact of subsidized investment on low-income neighborhoods.

While not conclusive, these results also suggest that to the extent that there is crowd out associated with the NMTC program, it is not complete. This finding is consistent with GurleyCalvez et al. (2009), who analyze individual and corporate income tax data and argue that the NMTC crowds out some, but not all private investment. The results are also in line with recent qualitative work on the NMTC, including studies by the U.S. Government Accountability Office (2007, 2010) and Abravanel et al. (2007). These reports suggest that while a concern, crowd out does not appear to be complete and that some projects would not be feasible without NMTC support. ${ }^{43}$ Further, both the GAO and Abravanel et al. conclude that although community

\footnotetext{
${ }^{42}$ A primary job represents the job that accounts for the largest fraction of an individual's annual earnings. The results are similar if one includes both primary and secondary jobs in the sample.

${ }^{43}$ In a survey by the U.S. Government Accountability Office (2007), 64\% of NMTC investors reported allocating more of their investment budget to LICs as a result of the credit. However, as the U.S. Government Accountability Office acknowledges, these investors have a vested interest in preserving the program, which may have colored their answers to the survey.
} 
benefits were not a chief concern in CDEs' selection of projects, there was some evidence that NMTC-subsidized investment in poor areas had positive spillovers.

\section{Conclusion}

Although place-based policies have grown in importance in recent decades, many remain skeptical of their efficacy. Lending credence to this skepticism are numerous studies on programs such as state EZs that suggest there is little to no benefit associated with subsidizing investment in struggling cities and neighborhoods. However, many of these studies have struggled themselves with identification, due in large part to self-selection of areas into placebased programs.

The paper adds to the literature on place-based programs by evaluating the effects of the New Markets Tax Credit (NMTC) program on neighborhoods. The structure of the program allows me to overcome endogeneity and selection problems that have plagued past studies on other place-based programs. In particular, a discontinuity in the formula used to determine program eligibility for census tracts generates pseudo-random assignment of NMTC-subsidized investment to neighborhoods around a certain income threshold. Tracts below the threshold are eligible to receive investment under the program, whereas those above it are generally not eligible. However, the tracts on either side of the threshold are otherwise similar. Hence, comparing outcomes among tracts within a sufficiently narrow window around the cutoff permits one to draw causal inferences regarding the effects of NMTC-subsidized investment on neighborhoods.

I find some evidence that investment subsidized under the NMTC program reduces poverty and unemployment rates in relatively low-income census tracts, although the results suggest that some of these effects are driven by changes in the composition of residents rather than improvement in the welfare of existing residents. The impacts on other neighborhood characteristics, including home values, are positive but statistically indistinguishable from zero. There is also some evidence to suggest that investment increases total private-sector employment and improves the quality of jobs in affected areas. However, the estimated effects are not large and are often statistically imprecise. I tentatively conclude that while there appear to be some positive effects of subsidized investment in disadvantaged neighborhoods, the benefits associated 
with subsidized investment are modest. This finding is consistent with results from studies on other place-based programs, such as the Low-Income Housing Tax Credit (Baum-Snow and Marion 2009) and the Community Reinvestment Act (Gabriel and Rosenthal 2009).

More broadly, this paper builds on a burgeoning literature exploiting geographic boundaries to identify the effects of various policies and programs. Research along these lines include studies on education (Black 1999), the environment (Ito 2011), social insurance programs (Lalive 2008), minimum wages (Dube et al. 2010), and other areas. Expanding on this literature, this paper exploits a discontinuous eligibility formula that generates quasi-experimental variation across geographies in subsidized investment to evaluate a large-scale place-based program that aims to reinvigorate distressed communities. While the NMTC program is still in its infancy and further research is necessary to establish its longer-run impacts on neighborhoods, this paper suggests that its initial effects may be positive, but not large.

\section{Acknowledgements}

I would like to thank John Abowd, David Card, Mark Duggan, George Jakubson, David Lee, Jeffrey Lin, Alexandre Mas, Jordan Matsudaira, Henry Overman, Emily Owens, Philip Tegeler, Brett Theodos, Lars Vilhuber, Jeffrey Zax, and two anonymous referees as well as seminar participants at Cornell University, the Federal Reserve Bank of Philadelphia, Princeton University, the University of Rochester, the Association for Public Policy Analysis and Management Meetings, and the Urban Economics Association Meetings for helpful comments. I would also like to thank Greg Bischak, Jim Greer, and Joseph Valenti at the Community Development Financial Institutions Fund at the U.S. Treasury for assistance with the data used in this study and for sharing their insights into the details of the New Markets Tax Credit program. The research reported in this article used resources provided by Cornell University's Social Science Gateway, which is funded through NSF Grant 0922005. All the views expressed in this paper are my own and in no way reflect those of the U.S. Department of the Treasury. 


\section{References}

Abravanel, Martin, Nancy Pindus, and Brett Theodos. 2007. "Analysis of Selected New Markets Tax Credit Projects." Urban Institute, Report for the US Department of Treasury, Community Development Financial Institutions Fund.

Anderson, T. W. and Herman Rubin. 1949. "Estimators of the Parameters of a Single Equation in a Complete Set of Stochastic Equations." Annals of Mathematical Statistics 20(1): 570-582.

Andersson, Fredrik, Matthew Freedman, Marc Roemer, and Lars Vilhuber. "LEHD OnTheMap Technical Documentation.” Technical Paper DATA-OTM-2.0.3, U.S. Census Bureau.

Armistead, P. Jefferson. 2005. "Is the NMTC Program Making a Difference in Low-Income Communities?” Community Development Investment Review 1(1): 13-20.

Baum-Snow, Nathaniel, and Justin Marion. 2009. "The Effects of Low-Income Housing Tax Credit Development on Neighborhoods.” Journal of Public Economics 93(5-6): 654-666.

Bhutta, Neil. 2010. "GSE Activity and Mortgage Supply in Lower-Income and Minority Neighborhoods: The Effect of the Affordable Housing Goals." The Journal of Real Estate Finance and Economics.

Billings, Stephen. 2009. "Do Enterprise Zones Work? An Analysis at the Borders.” Public Finance Review 37(1): 68-93.

Black, Sandra. 1999. "Do Better Schools Matter? Parental Valuation of Elementary Education." Quarterly Journal of Economics 114(2): 577-599.

Boarnet, Marlon and William Bogart. 1996. "Enterprise Zones and Employment: Evidence from New Jersey.” Journal of Urban Economics 40(2): 198-215.

Busso, Matias, Jesse Gregory, and Patrick Kline. 2011. “Assessing the Incidence and Efficiency of a Prominent Place Based Policy." Center for Economic Studies Working Paper CES-WP11-07, U.S. Census Bureau.

Chay, Kenneth and Michael Greenstone. 2005. "Does Air Quality Matter? Evidence from the Housing Market.” Journal of Political Economy 113(2): 376-424.

Chirinko, Robert and Daniel Wilson. 2008. "State Investment Tax Incentives: A Zero-Sum Game?" Journal of Public Economics 92(12): 2362-2384. 
Dube, Arindrajit, William Lester, and Michael Reich. 2010. "Minimum Wage Effects Across State Borders: Estimates Using Contiguous Counties." Review of Economics and Statistics 92(4): 945-964.

Elvery, Joel. 2009. "The Impact of Enterprise Zones on Residential Employment: An Evaluation of the Enterprise Zone Programs of California and Florida." Economic Development Quarterly 23(1): 44-59.

Eriksen, Michael and Stuart Rosenthal. 2010. "Crowd Out Effects of Place-Based Subsidized Rental Housing: New Evidence from the LIHTC Program.” Journal of Public Economics 94(11-12): 953-966.

Freedman, Matthew. 2012. "Targeted Business Incentives and Local Labor Markets." Cornell University Working Paper.

Freedman, Matthew and Emily Owens. 2011. "Low-Income Housing Development and Crime." Journal of Urban Economics 70(2-3): 115-131.

Gabriel, Stuart and Stuart Rosenthal. 2009. "Government-Sponsored Enterprises, the Community Reinvestment Act, and Homeownership in Targeted Underserved Neighborhoods." In Housing Markets and the Economy, eds. Edward Glaeser and John Quigley. Cambridge, MA: Lincoln Institute of Land Policy.

Glaeser, Edward and Joshua Gottlieb. 2008. "The Economics of Place-Making Policies." Brookings Papers on Economic Activity. 39(1): 155-253.

Greenstone, Michael and Enrico Moretti. 2004. "Bidding for Industrial Plants: Does Winning a ‘Million Dollar Plant' Increase Welfare?” NBER Working Paper 9844.

Gurley-Calvez, Tami, Thomas Gilbert, Katherine Harper, Donald Marples, and Kevin Daly. 2009. "Do Tax Incentives Affect Investment: An Analysis of the New Markets Tax Credit." Public Finance Review 37(4): 371-398.

Ham, John, Charles Swenson, Ayşe İmrohoroğlu, and Heonjae Song. 2011. "Government Programs Can Improve Local Labor Markets: Evidence from State Enterprise Zones, Federal Empowerment Zones, and Federal Enterprise Community.” Journal of Public Economics 95(7-8): 779-797.

Ito, Koichiro. 2011. "Do Consumers Respond to Marginal or Average Prices? Evidence from Nonlinear Electricity Pricing.” University of California-Berkeley Working Paper. 
Jacob, Brian and Lars Lefgren. 2004. "Remedial Education and Student Achievement: A Regression-Discontinuity Analysis." Review of Economics and Statistics 86(1): 226-244.

Lalive, Rafael. 2008. "How Do Extended Benefits Affect Unemployment Duration? A Regression Discontinuity Approach.” Journal of Econometrics 142(2): 785-806.

Lambie-Hanson, Lauren. 2008. "Assessing the Prevalence of Real Estate Investments in the New Markets Tax Credit Program.” Federal Reserve Bank of San Francisco, Community Development Investment Center Working Paper.

Lee, David. 2008. "Randomized Experiments from Non-Random Selection in U.S. House Elections." Journal of Econometrics 142(2): 675-697.

Lee, David and Thomas Lemieux. 2010. "Regression Discontinuity Designs in Economics." Journal of Economic Literature 48(2): 281-355.

Matsudaira, Jordan. 2008. "Mandatory Summer School and Student Achievement." Journal of Econometrics 142(2): 829-850.

McCrary, Justin. 2008. "Testing for Manipulation of the Running Variable in the Regression Discontinuity Design." Journal of Econometrics 142(2): 698-714.

Meyer, Bruce. 2010. "The Effects of the Earned Income Tax Credit and Recent Reforms." In Tax Policy and the Economy 24, Ed. Jeffrey Brown. Chicago: University of Chicago Press. Moreira, Marcelo. 2009. "Tests with Correct Size when Instruments Can Be Arbitrarily Weak." Journal of Econometrics 152(2): 131-140.

Neumark, David and Jed Kolko. 2010. "Do Enterprise Zones Create Jobs? Evidence from California's Enterprise Zone Program.” Journal of Urban Economics 68(1): 1-19.

Papke, Leslie. 1994. "Tax Policy and Urban Development: Evidence from the Indiana Enterprise Zone Program." Journal of Public Economics 54(1): 37-49.

Peters, Alan and Peter Fisher. 2002. State Enterprise Zones: Have They Worked? Kalamazoo, Michigan: W.E. Upjohn Institute for Employment Research.

Rubin, Julia, and Gregory Stankiewicz. 2005. "The New Markets Tax Credit Program: A Midcourse Assessment." Community Development Investment Review 1(1): 1-11.

Sinai, Todd and Joel Waldfogel. 2005. "Do Low-Income Housing Subsidies Increase the Occupied Housing Stock?" Journal of Public Economics 89(11-12): 2137-2164. 
Staiger, Douglas, and James Stock. 1997. "Instrumental Variables Regression with Weak Instruments." Econometrica 65(3): 557-586.

U.S. Government Accountability Office. 2007. "Tax Policy: New Markets Tax Credit Appears to Increase Investment by Investors in Low-Income Communities, but Opportunities Exist to Better Monitor Compliance." GAO-07-296. . 2010. "New Markets Tax Credit: The Credit Helps Fund a Variety of Projects in LowIncome Communities, But Could Be Simplified.” GAO-10-334. 
Table 1

Descriptive Statistics for Recipient and Non-Recipient Tracts

\begin{tabular}{|c|c|c|c|c|}
\hline & \multicolumn{2}{|c|}{ All Tracts } & \multicolumn{2}{|c|}{ Low-Income Communities } \\
\hline & $\begin{array}{c}\text { Tracts } \\
\text { Receiving } \\
\text { Investment }\end{array}$ & $\begin{array}{c}\text { Tracts Not } \\
\text { Receiving } \\
\text { Investment } \\
\end{array}$ & $\begin{array}{c}\text { Tracts } \\
\text { Receiving } \\
\text { Investment }\end{array}$ & $\begin{array}{c}\text { Tracts Not } \\
\text { Receiving } \\
\text { Investment } \\
\end{array}$ \\
\hline \multicolumn{5}{|c|}{ A. Demographic Characteristics (2000) } \\
\hline Population & 3884 & 4378 & 3854 & 3982 \\
\hline Share of Pop. Black & 0.28 & 0.13 & 0.29 & 0.24 \\
\hline Share of Pop. Hispanic & 0.20 & 0.11 & 0.21 & 0.19 \\
\hline Share of Pop. Under Age 5 & 0.07 & 0.07 & 0.07 & 0.07 \\
\hline Share of Pop. $65+$ & 0.12 & 0.13 & 0.12 & 0.13 \\
\hline Share of Pop. Enrolled in School & 0.29 & 0.28 & 0.29 & 0.29 \\
\hline Share of Pop. Less Than HS Degree & 0.33 & 0.20 & 0.34 & 0.31 \\
\hline Share of Pop. With Just HS Degree & 0.29 & 0.29 & 0.29 & 0.32 \\
\hline Share of Pop. With Some College & 0.23 & 0.27 & 0.23 & 0.24 \\
\hline Share of Pop. With Bachelor's or More & 0.15 & 0.23 & 0.14 & 0.13 \\
\hline Average Household Size & 2.58 & 2.63 & 2.58 & 2.68 \\
\hline Median HH Income (\$) & 27,659 & 45,185 & 27,055 & 29,392 \\
\hline Poverty Rate & 0.26 & 0.13 & 0.26 & 0.22 \\
\hline Unemployment Rate & 0.11 & 0.06 & 0.11 & 0.10 \\
\hline \multicolumn{5}{|c|}{ B. Housing Characteristics (2000) } \\
\hline Number of Housing Units & 1620 & 1807 & 1600 & 1646 \\
\hline Share Vacant & 0.11 & 0.08 & 0.11 & 0.11 \\
\hline Share Occupied & 0.89 & 0.92 & 0.89 & 0.89 \\
\hline Share Owner Occupied & 0.38 & 0.62 & 0.37 & 0.47 \\
\hline Share Renter Occupied & 0.51 & 0.30 & 0.52 & 0.41 \\
\hline Share Owner Occupied w/ Mortgage & 0.65 & 0.68 & 0.65 & 0.61 \\
\hline Median Age of Housing Units & 42.40 & 33.79 & 42.81 & 39.58 \\
\hline Median Number of Rooms & 4.42 & 5.43 & 4.38 & 4.78 \\
\hline Median House Value (\$) & 106,662 & 139,238 & 105,723 & 92,234 \\
\hline Share in Diff. Residence 1 Year Ago & 0.25 & 0.19 & 0.25 & 0.22 \\
\hline \multicolumn{5}{|c|}{ C. Changes in Neighborhood Characteristics (2000 to 2005-2009) } \\
\hline Change in Log Home Values & 0.56 & 0.47 & 0.57 & 0.49 \\
\hline Change in Log Median HH Income & 0.19 & 0.18 & 0.20 & 0.18 \\
\hline Change in Poverty Rate ${ }^{\dagger}$ & 1.18 & 1.62 & 1.15 & 1.67 \\
\hline Change in Unemployment $\operatorname{Rate}^{\dagger}$ & 0.18 & 1.52 & 0.14 & 1.10 \\
\hline Change in Household Turnover ${ }^{\dagger}$ & -2.27 & -3.46 & -2.21 & -3.09 \\
\hline Tracts & 1538 & 60,717 & 1474 & 22,224 \\
\hline
\end{tabular}

Notes: Excludes tracts in GO Zones and that are missing 2000 Census or 2005-2009 ACS data. ${ }^{\dagger}$ Measured in percentage points. 
Table 2

Descriptive Statistics Near the MFI Eligibility Threshold

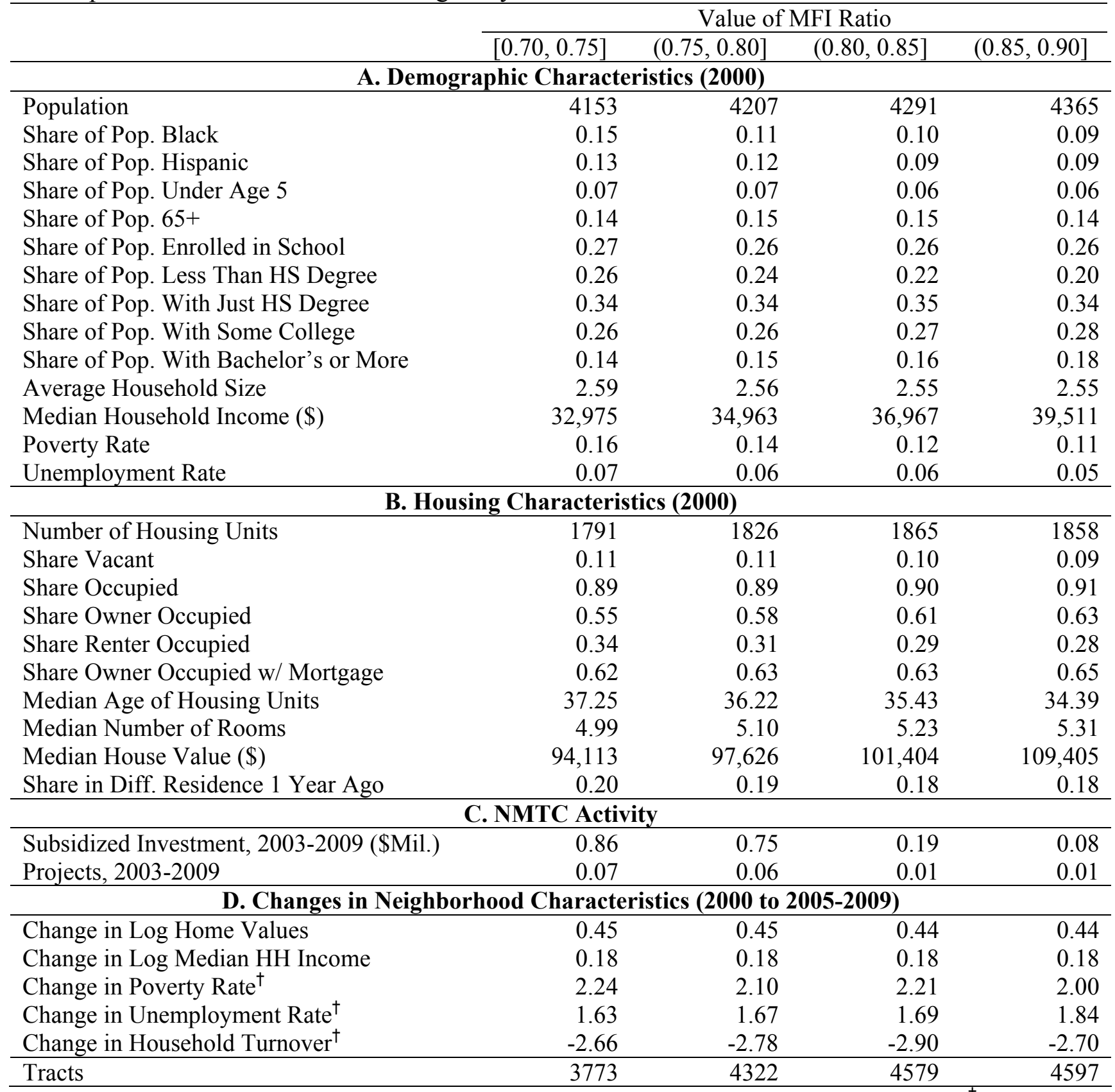

Notes: Excludes tracts in GO Zones and that are missing 2000 Census or 2005-2009 ACS data. ${ }^{\dagger}$ Measured in percentage points. 


\section{Table 3}

Tract-Level Investment Location Estimates

\begin{tabular}{|c|c|c|c|c|c|c|}
\hline & $(1)$ & $(2)$ & (3) & (4) & $(5)$ & (6) \\
\hline NMTC Investment, 2003-2009 (Mil.) & $\begin{array}{c}0.957 * * * \\
{[0.307]}\end{array}$ & $\begin{array}{c}0.899 * * * \\
{[0.296]}\end{array}$ & $\begin{array}{c}0.859 * * * \\
{[0.284]}\end{array}$ & $\begin{array}{c}1.110 * * * \\
{[0.359]}\end{array}$ & $\begin{array}{c}1.038 * * * \\
{[0.347]}\end{array}$ & $\begin{array}{c}0.979 * * * \\
{[0.326]}\end{array}$ \\
\hline NMTC Projects, 2003-2009 & $\begin{array}{c}0.048 * * * \\
{[0.013]}\end{array}$ & $\begin{array}{c}0.044 * * * \\
{[0.013]}\end{array}$ & $\begin{array}{c}0.043 * * * \\
{[0.012]}\end{array}$ & $\begin{array}{c}0.047 * * * \\
{[0.013]}\end{array}$ & $\begin{array}{c}0.044 * * * \\
{[0.013]}\end{array}$ & $\begin{array}{c}0.043 * * * \\
{[0.013]}\end{array}$ \\
\hline Cubic in MFI Ratio & $\mathrm{Y}$ & $\mathrm{Y}$ & $\mathrm{Y}$ & & & \\
\hline Quartic in MFI Ratio & & & & $\mathrm{Y}$ & Y & $\mathrm{Y}$ \\
\hline County Dummies & Y & Y & $\mathrm{Y}$ & Y & Y & $\mathrm{Y}$ \\
\hline Demographic Controls & & Y & $\mathrm{Y}$ & & $\mathrm{Y}$ & $\mathrm{Y}$ \\
\hline Housing Controls & & & Y & & & Y \\
\hline Observations & 17271 & 17271 & 17271 & 17271 & 17271 & 17271 \\
\hline
\end{tabular}

Notes: Includes tracts with income ratios between 0.7 and 0.9 (inclusive) that are not in GO Zones and that are not missing 2000 Census or 2005-2009 ACS data. Demographic controls include log population, share black, share Hispanic, share under age 5, share 65 and over, share enrolled in school, share with less than a HS degree, share with HS degree, share with some college, share with bachelor's or more, and average household size. Housing controls include log number of units, share vacant, share owner occupied, share with mortgage, median age of units, and median number of rooms. Standard errors are adjusted for heteroskedasticity and clusters at the county level. Significant at the * 10\% level, ** 5\% level, and *** $1 \%$ level. 
Table 4

Tract-Level OLS and IV Estimates

\begin{tabular}{|c|c|c|c|c|c|c|}
\hline & $(1)$ & $(2)$ & $(3)$ & $(4)$ & $(5)$ & $(6)$ \\
\hline \multicolumn{7}{|c|}{ A. OLS Results } \\
\hline Change in Log Median Home Value & $\begin{array}{c}-0.0003 \\
{[0.0004]}\end{array}$ & $\begin{array}{c}-0.0003 \\
{[0.0004]}\end{array}$ & $\begin{array}{c}-0.0001 \\
{[0.0003]}\end{array}$ & $\begin{array}{c}-0.0003 \\
{[0.0004]}\end{array}$ & $\begin{array}{c}-0.0003 \\
{[0.0004]}\end{array}$ & $\begin{array}{c}-0.0001 \\
{[0.0003]}\end{array}$ \\
\hline Change in Log Median Household Income & $\begin{array}{c}0.0002 \\
{[0.0001]}\end{array}$ & $\begin{array}{c}0.0002 * \\
{[0.0001]}\end{array}$ & $\begin{array}{l}0.0002 * * \\
{[0.0001]}\end{array}$ & $\begin{array}{c}0.0002 \\
{[0.0001]}\end{array}$ & $\begin{array}{c}0.0002 * \\
{[0.0001]}\end{array}$ & $\begin{array}{l}0.0002 * * \\
{[0.0001]}\end{array}$ \\
\hline Change in Poverty Rate & $\begin{array}{c}-0.0022 \\
{[0.0063]}\end{array}$ & $\begin{array}{l}-0.0025 \\
{[0.0060]}\end{array}$ & $\begin{array}{c}-0.0033 \\
{[0.0062]}\end{array}$ & $\begin{array}{l}-0.0021 \\
{[0.0063]}\end{array}$ & $\begin{array}{c}-0.0024 \\
{[0.0060]}\end{array}$ & $\begin{array}{c}-0.0032 \\
{[0.0061]}\end{array}$ \\
\hline Change in Unemployment Rate & $\begin{array}{l}-0.0088^{*} \\
{[0.0045]}\end{array}$ & $\begin{array}{c}-0.0068 \\
{[0.0043]}\end{array}$ & $\begin{array}{c}-0.0068 \\
{[0.0042]}\end{array}$ & $\begin{array}{l}-0.0088^{*} \\
{[0.0045]}\end{array}$ & $\begin{array}{c}-0.0068 \\
{[0.0043]}\end{array}$ & $\begin{array}{c}-0.0068 \\
{[0.0042]}\end{array}$ \\
\hline Change in Household Turnover & $\begin{array}{c}0.0035 \\
{[0.0090]}\end{array}$ & $\begin{array}{c}0.0016 \\
{[0.0079]}\end{array}$ & $\begin{array}{c}0.0094 \\
{[0.0071]} \\
\end{array}$ & $\begin{array}{c}0.0034 \\
{[0.0090]}\end{array}$ & $\begin{array}{c}0.0016 \\
{[0.0079]}\end{array}$ & $\begin{array}{c}0.0093 \\
{[0.0071]}\end{array}$ \\
\hline \multicolumn{7}{|c|}{ B. IV Results } \\
\hline Change in Log Median Home Value & $\begin{array}{c}0.0211 \\
{[0.0160]}\end{array}$ & $\begin{array}{c}0.0238 \\
{[0.0164]}\end{array}$ & $\begin{array}{c}0.0228 \\
{[0.0157]}\end{array}$ & $\begin{array}{c}0.0148 \\
{[0.0170]}\end{array}$ & $\begin{array}{c}0.0169 \\
{[0.0173]}\end{array}$ & $\begin{array}{c}0.0189 \\
{[0.0168]}\end{array}$ \\
\hline Change in Log Median Household Income & $\begin{array}{c}-0.0018 \\
{[0.0075]}\end{array}$ & $\begin{array}{c}0.0040 \\
{[0.0079]}\end{array}$ & $\begin{array}{c}0.0079 \\
{[0.0083]}\end{array}$ & $\begin{array}{c}-0.0041 \\
{[0.0079]}\end{array}$ & $\begin{array}{c}0.0007 \\
{[0.0081]}\end{array}$ & $\begin{array}{c}0.0029 \\
{[0.0085]}\end{array}$ \\
\hline Change in Poverty Rate & $\begin{array}{c}-0.8049 * * \\
{[0.3915]}\end{array}$ & $\begin{array}{c}-1.0027 * * \\
{[0.4504]}\end{array}$ & $\begin{array}{c}-1.1247 * * \\
{[0.4806]}\end{array}$ & $\begin{array}{c}-0.5520 \\
{[0.3572]}\end{array}$ & $\begin{array}{l}-0.7183^{*} \\
{[0.4021]}\end{array}$ & $\begin{array}{c}-0.8097^{*} \\
{[0.4275]}\end{array}$ \\
\hline Change in Unemployment Rate & $\begin{array}{c}-0.3815 \\
{[0.2384]}\end{array}$ & $\begin{array}{c}-0.2987 \\
{[0.2403]}\end{array}$ & $\begin{array}{c}-0.2701 \\
{[0.2428]}\end{array}$ & $\begin{array}{l}-0.4476^{*} \\
{[0.2497]}\end{array}$ & $\begin{array}{c}-0.3626 \\
{[0.2494]}\end{array}$ & $\begin{array}{c}-0.3408 \\
{[0.2553]}\end{array}$ \\
\hline Change in Household Turnover & $\begin{array}{c}0.7266^{*} \\
{[0.4086]}\end{array}$ & $\begin{array}{c}0.5493 \\
{[0.4063]}\end{array}$ & $\begin{array}{c}0.6208 \\
{[0.4207]}\end{array}$ & $\begin{array}{l}0.8265^{*} \\
{[0.4437]}\end{array}$ & $\begin{array}{c}0.7159 \\
{[0.4368]}\end{array}$ & $\begin{array}{l}0.8252^{*} \\
{[0.4658]}\end{array}$ \\
\hline Cubic in MFI Ratio & $\mathrm{Y}$ & $\mathrm{Y}$ & $\mathrm{Y}$ & & & \\
\hline Quartic in MFI Ratio & & & & $\mathrm{Y}$ & $\mathrm{Y}$ & $\mathrm{Y}$ \\
\hline County Dummies & $\mathrm{Y}$ & Y & $\mathrm{Y}$ & $\mathrm{Y}$ & $\mathrm{Y}$ & $\mathrm{Y}$ \\
\hline Demographic Controls & & $\mathrm{Y}$ & Y & & $\mathrm{Y}$ & Y \\
\hline Housing Controls & & & $\mathrm{Y}$ & & & $\mathrm{Y}$ \\
\hline Observations & 17271 & 17271 & 17271 & 17271 & 17271 & 17271 \\
\hline
\end{tabular}

Notes: Includes tracts with income ratios between 0.7 and 0.9 (inclusive) that are not in GO Zones and that are not missing 2000

Census or 2005-2009 ACS data. Demographic controls and housing controls are the same as in Table 3. Standard errors are adjusted for heteroskedasticity and clusters at the county level. Significant at the * $10 \%$ level, ** 5\% level, and *** $1 \%$ level. 


\section{Table 5}

Tract-Level IV Estimates, Excluding Tracts with Poverty Rates Exceeding 20\%

\begin{tabular}{|c|c|c|c|c|c|c|}
\hline \multirow{3}{*}{ Change in Log Median Home Value } & $(1)$ & $(2)$ & (3) & (4) & $(5)$ & $(6)$ \\
\hline & 0.0272 & 0.0364 & 0.0403 & 0.0091 & 0.0175 & 0.0250 \\
\hline & {$[0.0334]$} & {$[0.0341]$} & {$[0.0355]$} & {$[0.0298]$} & {$[0.0290]$} & {$[0.0295]$} \\
\hline \multirow[t]{2}{*}{ Change in Log Median Household Income } & 0.0093 & 0.0135 & 0.0174 & -0.0010 & 0.0029 & 0.0026 \\
\hline & {$[0.0155]$} & {$[0.0157]$} & {$[0.0174]$} & {$[0.0138]$} & {$[0.0134]$} & [0.0139] \\
\hline \multirow[t]{2}{*}{ Change in Poverty Rate } & -0.3862 & -0.4826 & -0.5571 & -0.0075 & -0.0975 & -0.0935 \\
\hline & {$[0.6354]$} & {$[0.6348]$} & [0.6799] & {$[0.5355]$} & {$[0.5313]$} & {$[0.5525]$} \\
\hline \multirow[t]{2}{*}{ Change in Unemployment Rate } & -0.3523 & -0.4190 & -0.4212 & -0.2982 & -0.3200 & -0.3064 \\
\hline & {$[0.4608]$} & {$[0.4619]$} & {$[0.4787]$} & {$[0.4107]$} & {$[0.4068]$} & {$[0.4157]$} \\
\hline \multirow[t]{2}{*}{ Change in Household Turnover } & 0.1722 & 0.2028 & 0.3695 & 0.4763 & 0.5119 & 0.6347 \\
\hline & {$[0.7332]$} & {$[0.7106]$} & {$[0.7501]$} & {$[0.7006]$} & {$[0.6751]$} & [0.7096] \\
\hline Cubic in MFI Ratio & $\mathrm{Y}$ & $\mathrm{Y}$ & $\mathrm{Y}$ & & & \\
\hline Quartic in MFI Ratio & & & & Y & Y & $\mathrm{Y}$ \\
\hline County Dummies & $\mathrm{Y}$ & $\mathrm{Y}$ & Y & Y & $\mathrm{Y}$ & $\mathrm{Y}$ \\
\hline Demographic Controls & & $\mathrm{Y}$ & Y & & $\mathrm{Y}$ & $\mathrm{Y}$ \\
\hline Housing Controls & & & $\mathrm{Y}$ & & & $\mathrm{Y}$ \\
\hline Observations & 15349 & 15349 & 15349 & 15349 & 15349 & 15349 \\
\hline
\end{tabular}

Notes: Includes tracts with income ratios between 0.7 and 0.9 (inclusive), with poverty rates less than $20 \%$, and that are not in GO Zones or missing 2000 Census or 2005-2009 ACS data. Demographic controls and housing controls are the same as in Table 3. Standard errors are adjusted for heteroskedasticity and clusters at the county level. Significant at the * $10 \%$ level, ** 5\% level, and *** $1 \%$ level. 
Table 6

Tract-Level IV Estimates, Tests for Spillovers

\begin{tabular}{|c|c|c|c|c|c|c|}
\hline & (1) & (2) & (3) & (4) & (5) & (6) \\
\hline & Excl. Col & y Effects & $\begin{array}{r}\text { Excl. Inel } \\
\text { Count }\end{array}$ & $\begin{array}{l}\text { Tracts in } \\
\text { / LICs }\end{array}$ & $\begin{array}{c}\text { Excl. N } \\
\text { Ineligi }\end{array}$ & $\begin{array}{l}\text { oring } \\
\text { racts }\end{array}$ \\
\hline \multirow[t]{2}{*}{ Change in Log Home Values } & 0.0066 & 0.0004 & 0.0909 & 0.0483 & 0.0165 & 0.0015 \\
\hline & {$[0.0175]$} & {$[0.0159]$} & {$[0.0945]$} & {$[0.0528]$} & {$[0.0154]$} & {$[0.0154]$} \\
\hline \multirow[t]{2}{*}{ Change in Log Median Household Income } & -0.0008 & 0.0039 & -0.0136 & -0.0061 & -0.0051 & 0.0018 \\
\hline & {$[0.0081]$} & {$[0.0081]$} & {$[0.0246]$} & {$[0.0153]$} & {$[0.0088]$} & {$[0.0105]$} \\
\hline \multirow[t]{2}{*}{ Change in Poverty Rate } & $-1.0309 * *$ & $-1.1535 * *$ & -1.8442 & -1.1863 & -0.4456 & -0.6824 \\
\hline & {$[0.4603]$} & {$[0.4978]$} & {$[1.3797]$} & {$[0.8592]$} & {$[0.3997]$} & {$[0.4947]$} \\
\hline \multirow[t]{2}{*}{ Change in Unemployment Rate } & $-0.5487^{*}$ & -0.3512 & -0.8780 & -0.5459 & 0.0695 & 0.1617 \\
\hline & {$[0.2823]$} & {$[0.2551]$} & {$[0.9077]$} & {$[0.5767]$} & {$[0.2357]$} & {$[0.2800]$} \\
\hline \multirow[t]{2}{*}{ Change in Household Turnover } & $0.9394 * *$ & 0.5271 & 2.0601 & 0.8952 & 0.0452 & -0.4761 \\
\hline & {$[0.4677]$} & {$[0.4052]$} & {$[1.4914]$} & {$[0.7894]$} & {$[0.4290]$} & {$[0.5044]$} \\
\hline Cubic in MFI Ratio & $\mathrm{Y}$ & $\mathrm{Y}$ & $\mathrm{Y}$ & $\mathrm{Y}$ & $\mathrm{Y}$ & $\mathrm{Y}$ \\
\hline County Dummies & & & & & $\mathrm{Y}$ & $\mathrm{Y}$ \\
\hline State Dummies & $\mathrm{Y}$ & $\mathrm{Y}$ & $\mathrm{Y}$ & Y & & \\
\hline Demographic \& Housing Controls & & $\mathrm{Y}$ & & $\mathrm{Y}$ & & $\mathrm{Y}$ \\
\hline Observations & 17271 & 17271 & 9635 & 9635 & 10684 & 10684 \\
\hline
\end{tabular}

Notes: Includes tracts with income ratios between 0.7 and 0.9 (inclusive) that are not in GO Zones and that are not missing 2000 Census or 2005-2009 ACS data. Demographic controls and housing controls are the same as in Table 3. Standard errors are adjusted for heteroskedasticity and clusters at the county level. Significant at the * $10 \%, * * 5 \%$, and $* * * 1 \%$ level. 
Table 7

Tract-Level IV Estimates, Employment and Job Composition

\begin{tabular}{|c|c|c|c|c|c|c|}
\hline \multirow{3}{*}{ Change in Log Private Employment } & $(1)$ & $(2)$ & $(3)$ & $(4)$ & $(5)$ & $(6)$ \\
\hline & 0.0117 & 0.0130 & 0.0129 & 0.0168 & 0.0185 & 0.0163 \\
\hline & {$[0.0319]$} & [0.0339] & {$[0.0355]$} & {$[0.0310]$} & {$[0.0331]$} & {$[0.0343]$} \\
\hline \multirow[t]{2}{*}{ Change in Percentage Jobs Paying $<\$ 15 \mathrm{~K} /$ Year } & -1.0575 & -1.0640 & -1.1296 & $-1.2601 *$ & -1.2670 & -1.3487 \\
\hline & {$[0.6821]$} & {$[0.7217]$} & {$[0.7695]$} & {$[0.7442]$} & {$[0.7891]$} & {$[0.8419]$} \\
\hline \multirow[t]{2}{*}{ Change in Percentage Jobs Paying $\$ 15 \mathrm{~K}-\$ 40 \mathrm{~K} /$ Year } & 0.4738 & 0.5007 & 0.5676 & 0.4574 & 0.4624 & 0.5191 \\
\hline & {$[0.5450]$} & {$[0.5854]$} & {$[0.6240]$} & {$[0.5570]$} & {$[0.5973]$} & {$[0.6328]$} \\
\hline \multirow[t]{2}{*}{ Change in Percentage Jobs Paying $\$ 40 \mathrm{~K}+/$ Year } & 0.5838 & 0.5632 & 0.5620 & 0.8027 & 0.8046 & 0.8296 \\
\hline & {$[0.5777]$} & {$[0.6042]$} & {$[0.6371]$} & {$[0.6329]$} & {$[0.6587]$} & {$[0.6961]$} \\
\hline Cubic in MFI Ratio & $\mathrm{Y}$ & $\mathrm{Y}$ & $\mathrm{Y}$ & & & \\
\hline Quartic in MFI Ratio & & & & $\mathrm{Y}$ & $\mathrm{Y}$ & $\mathrm{Y}$ \\
\hline County Dummies & $\mathrm{Y}$ & $\mathrm{Y}$ & $\mathrm{Y}$ & $\mathrm{Y}$ & $\mathrm{Y}$ & $\mathrm{Y}$ \\
\hline Demographic Controls & & $\mathrm{Y}$ & Y & & $\mathrm{Y}$ & $\mathrm{Y}$ \\
\hline Housing Controls & & & $\mathrm{Y}$ & & & Y \\
\hline Observations & 16167 & 16167 & 16167 & 16167 & 16167 & 16167 \\
\hline
\end{tabular}

Notes: Includes tracts with income ratios between 0.7 and 0.9 (inclusive) that are not in GO Zones and that are not missing 2000 Census or 2005-2009 ACS data. Excludes AZ, AR, DC, MA, MS, and NH and tracts with fewer than 20 jobs. Demographic controls and housing controls are the same as in Table 3. Standard errors are adjusted for heteroskedasticity and clusters at the county level. Significant at the * $10 \%$ level, ** 5\% level, and *** $1 \%$ level. 


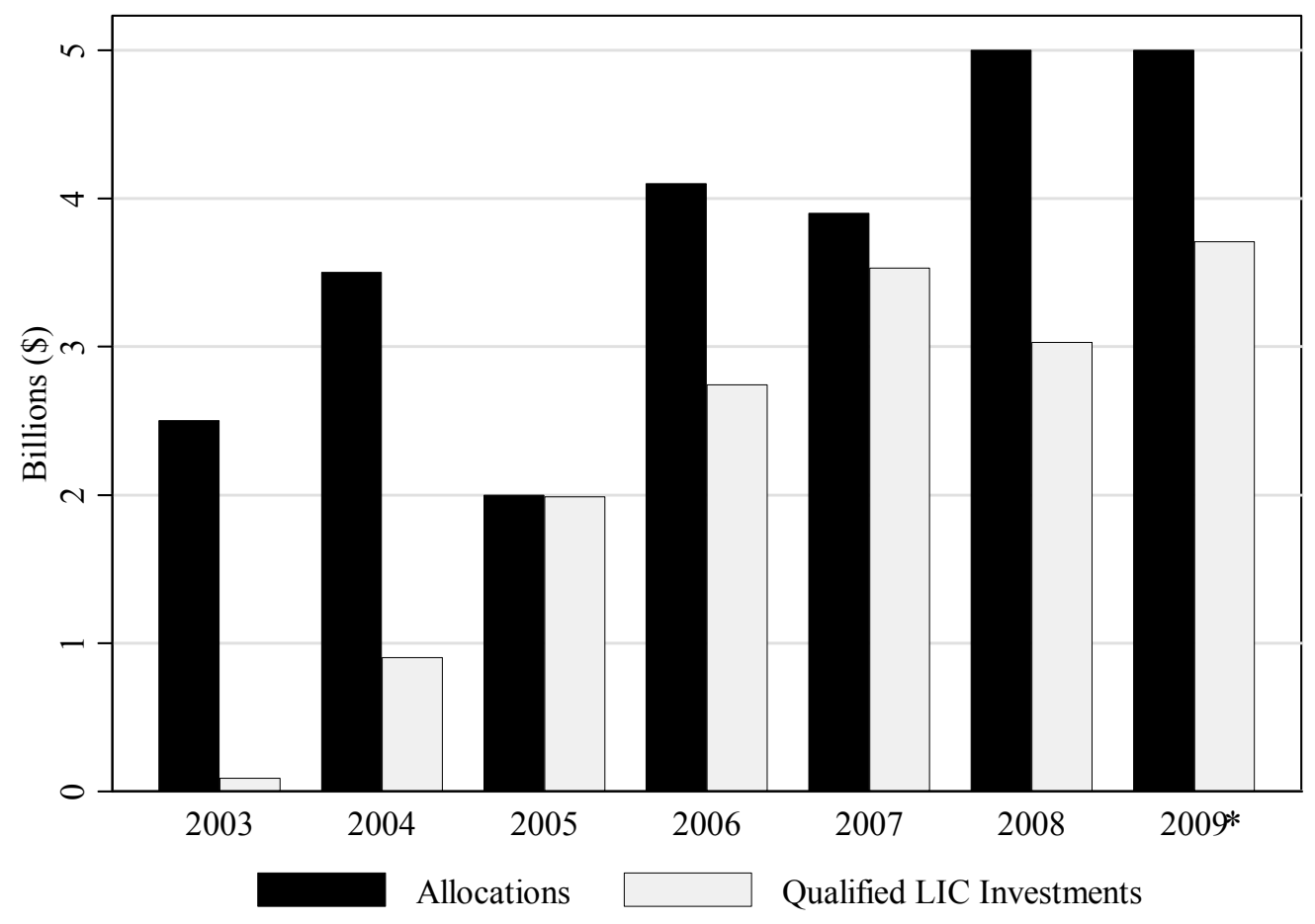

Fig. 1. NMTC allocations and qualified LIC investments by fiscal year. * Data on qualified LIC investments for 2009 only include investments reported through December 2009. 


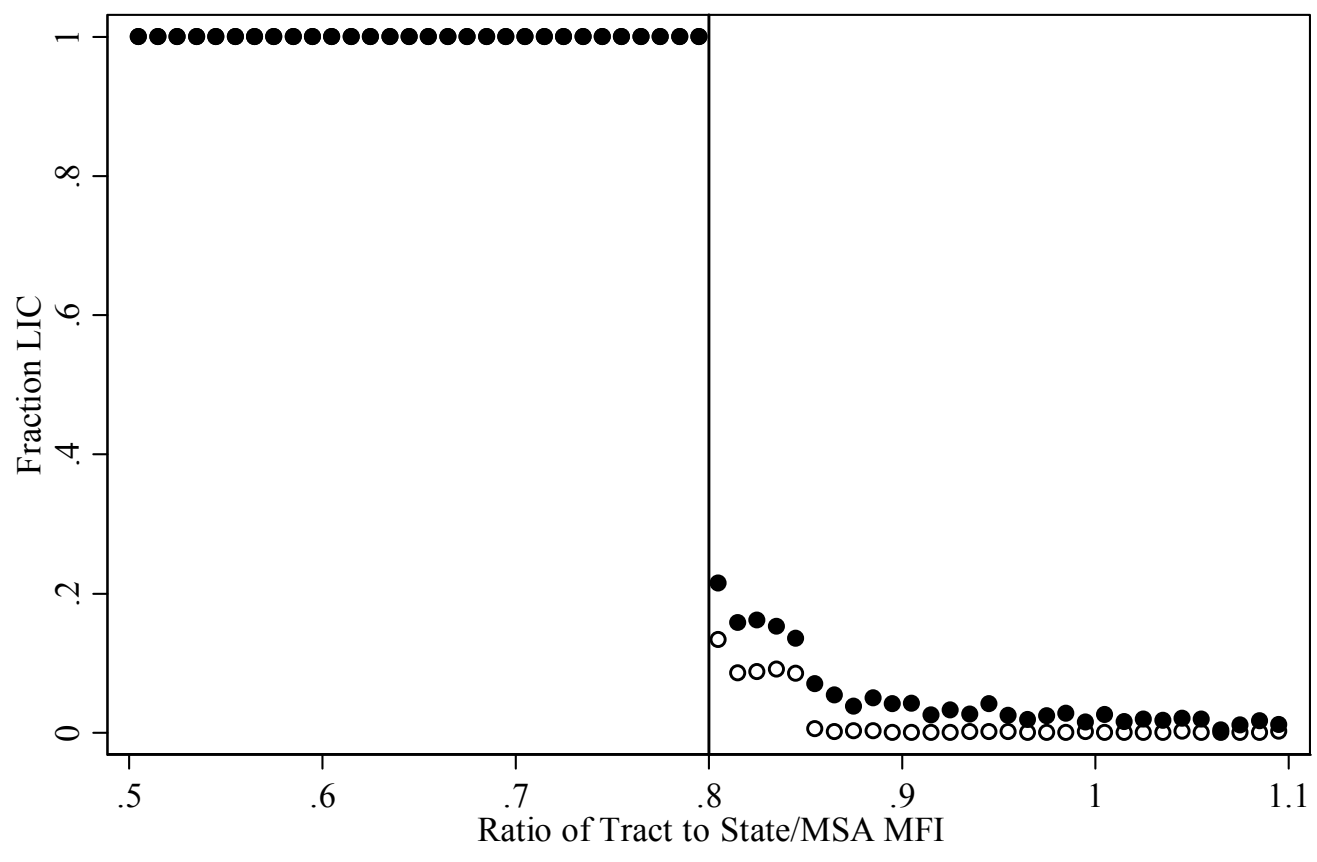

- Full Sample $\bigcirc$ Excluding Tracts with Poverty Rates $<=20 \%$

Fig. 2. Fraction of tracts that are LICs around the MFI ratio threshold. Bin size $=0.01$. 


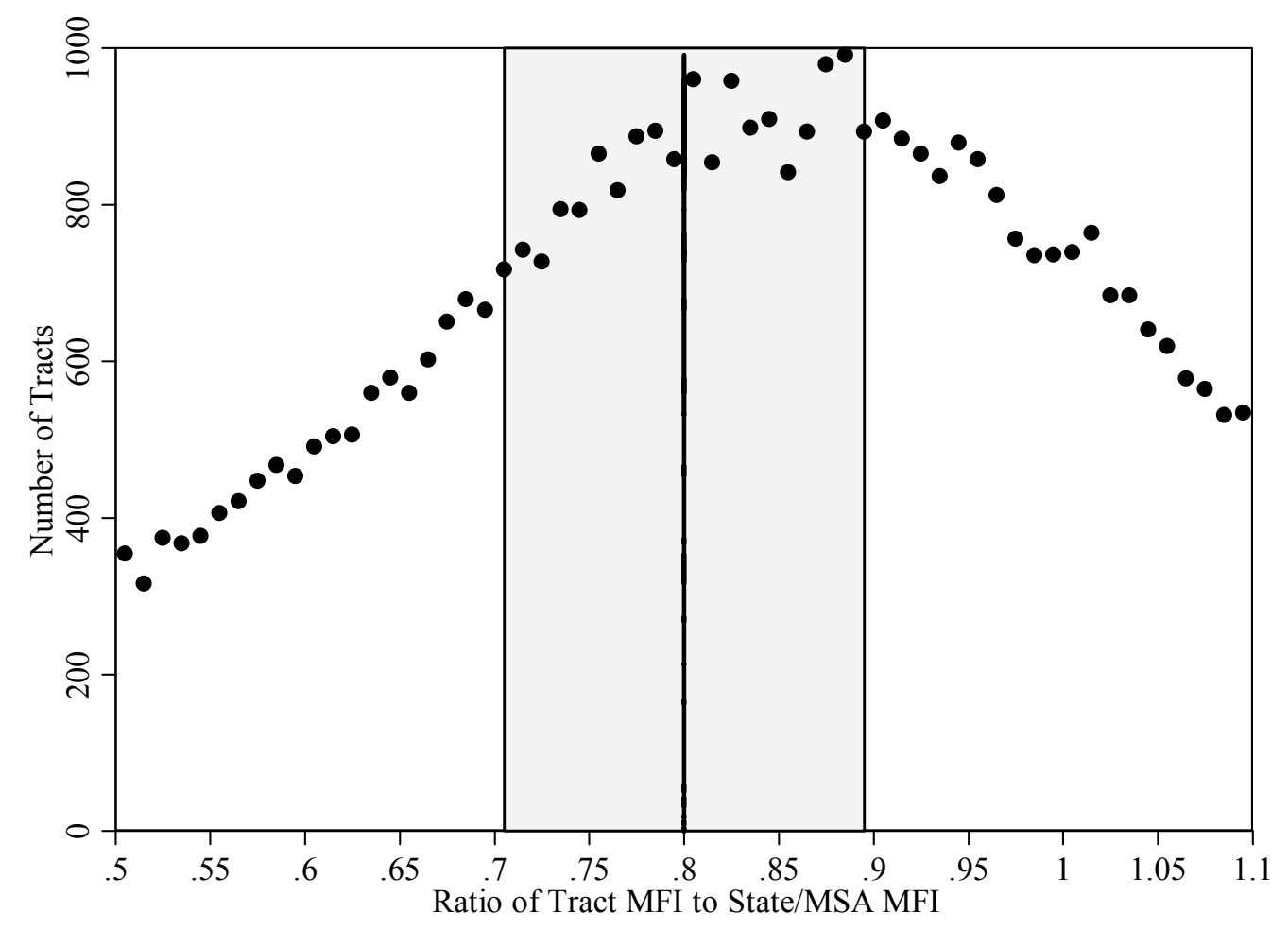

Fig. 3. Density of the forcing variable. Bin size $=0.01$ 
A. NMTC-Subsidized Investment (Mil. \$)

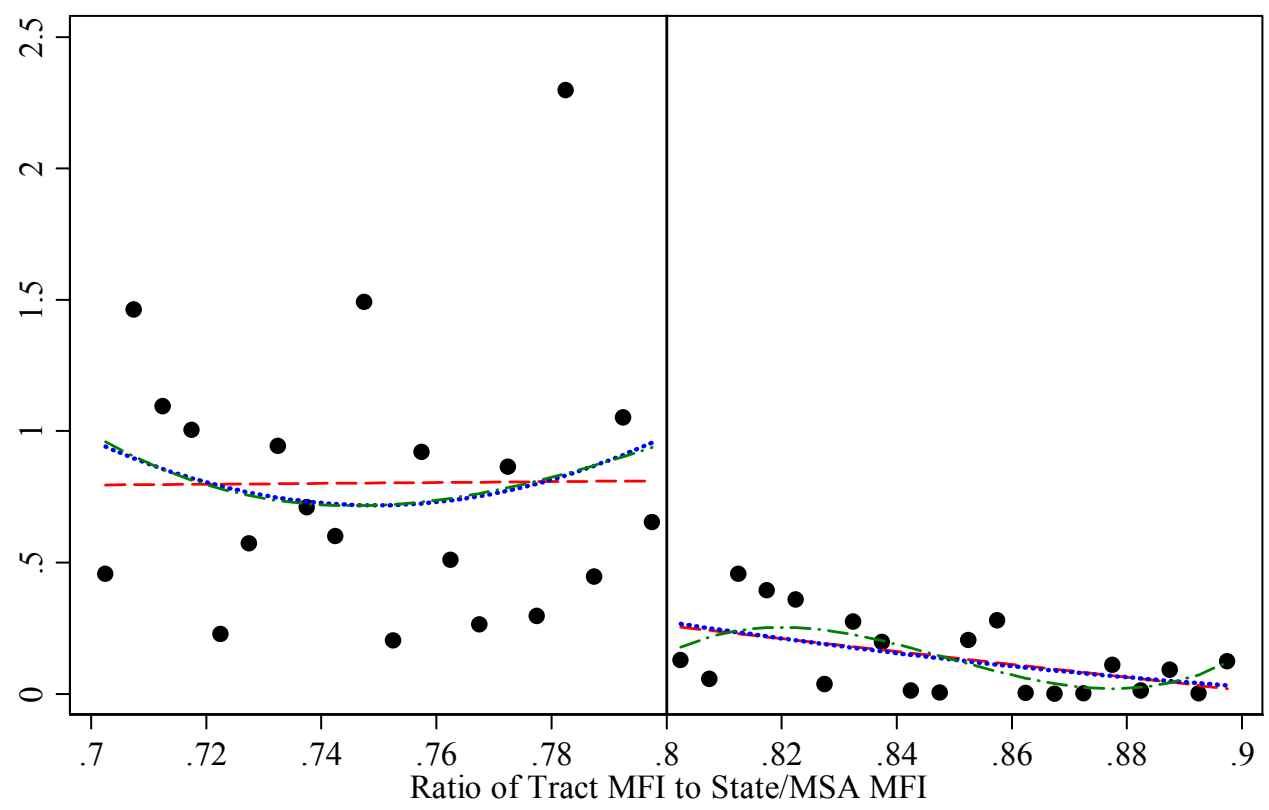

- --- Linear Fit $\quad$.................. Quadratic Fit $\quad-\cdot-\cdot-\cdot$ Cubic Fit

B. NMTC-Subsidized Projects

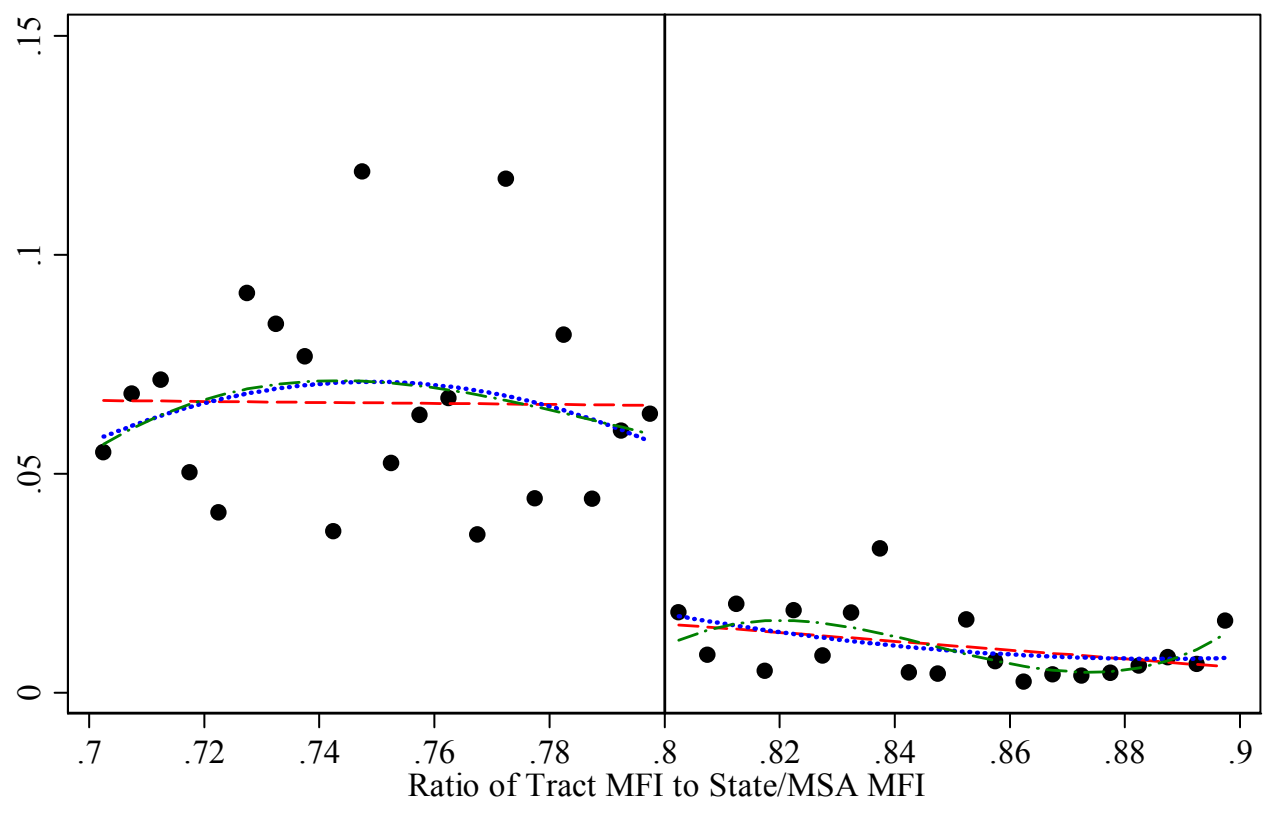

----- Linear Fit $\quad$................ Quadratic Fit $\quad-\cdot-\cdot-\cdot$ Cubic Fit

Fig. 4. NMTC-subsidized investment at the LIC MFI ratio eligibility threshold, 2003-2009. Sample includes 17,271 tracts. Bin size $=0.005$. 


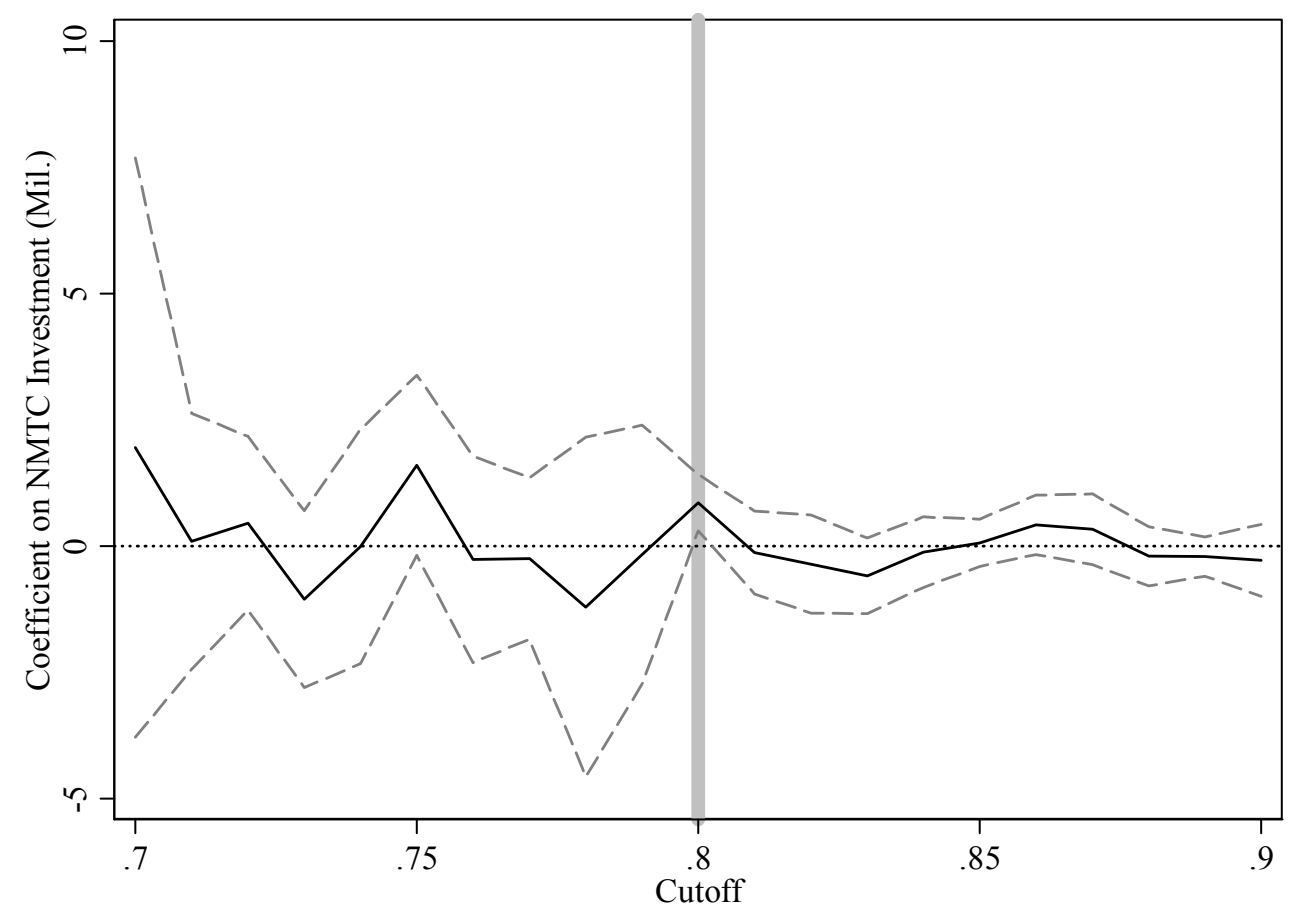

Fig. 5. Placebo tract-level NMTC-subsidized investment location estimates. Regressions include a cubic in the MFI ratio, county dummies, and demographic and housing controls. 
A. NMTC-Subsidized Investment (Mil. \$)

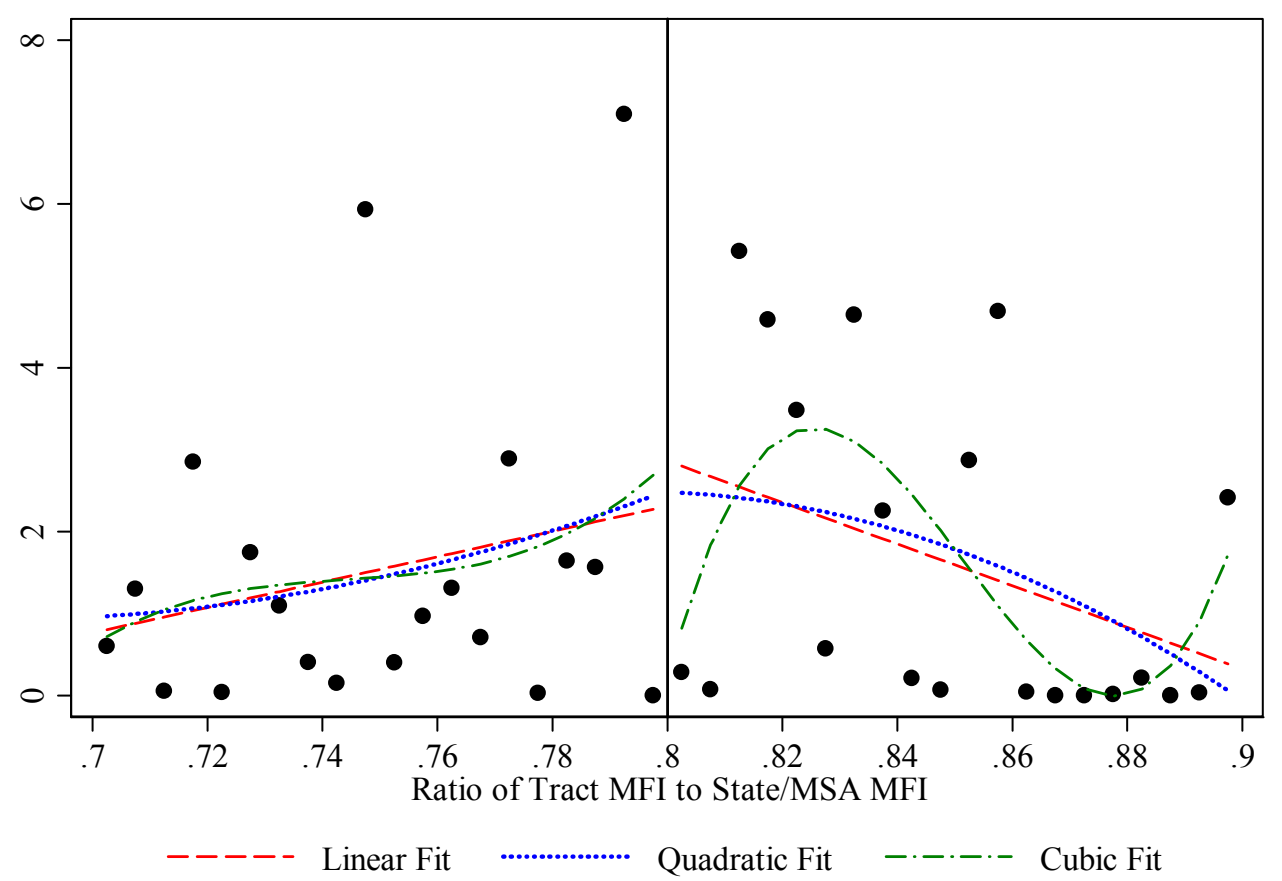

B. NMTC-Subsidized Projects

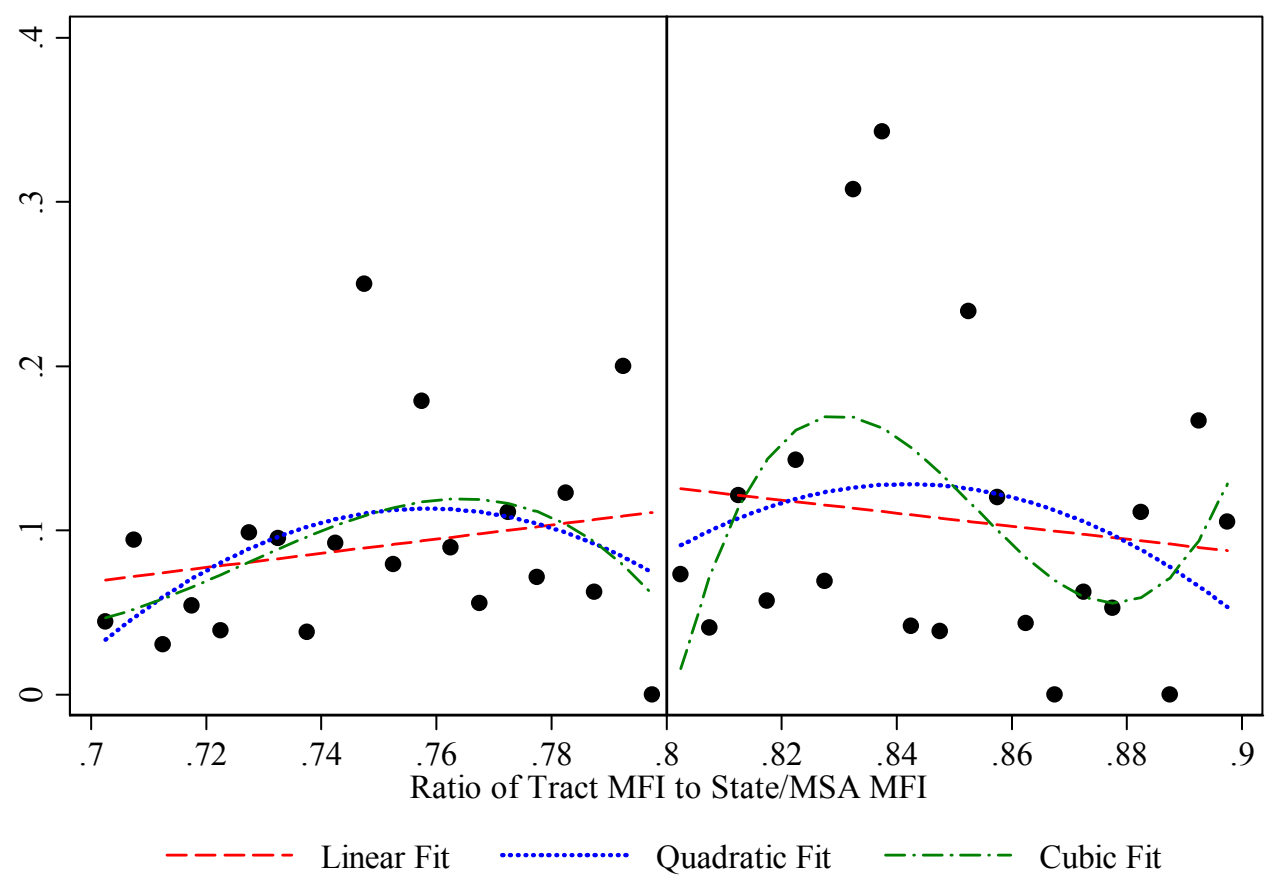

Fig. 6. NMTC-subsidized investment at the LIC MFI ratio eligibility threshold, including only tracts with poverty rates $\geq 20 \%, 2003-2009$. Sample includes 1,922 tracts. Bin size $=0.005$. 